NBER WORKING PAPER SERIES

\title{
EVALUATING THE ECONOMIC SIGNIFICANCE OF DOWNWARD NOMINAL WAGE RIGIDITY
}

\author{
Michael W. Elsby \\ Working Paper 12611 \\ http://www.nber.org/papers/w12611 \\ NATIONAL BUREAU OF ECONOMIC RESEARCH \\ 1050 Massachusetts Avenue \\ Cambridge, MA 02138 \\ October 2006
}

I am particularly grateful to my advisor, Alan Manning, for his perceptive comments and continued patience and encouragement. In addition I would like to thank Andrew Abel, Joseph Altonji, David Autor, Marianne Bertrand, Stephen Bond, Juan Dolado, Lorenz Goette, Maarten Goos, Steinar Holden, Francis Kramarz, Richard Layard, Stephen Machin, Jim Malcomson, Sendhil Mullainathan, Steve Pischke, Matthew Rabin, and Jennifer Smith for valuable comments. I would also like to thank seminar participants at the University of Michigan, Birkbeck, the Boston Fed, Chicago GSB, the CEPR ESSLE 2004, European Winter Meetings of the Econometric Society 2004, Federal Reserve Board, Oslo, Oxford, Stockholm IIES, Warwick, and Zurich, for helpful suggestions. Any errors are my own. The views expressed herein are those of the author(s) and do not necessarily reflect the views of the National Bureau of Economic Research.

(C) 2006 by Michael W. Elsby. All rights reserved. Short sections of text, not to exceed two paragraphs, may be quoted without explicit permission provided that full credit, including $\odot$ notice, is given to the source. 
Evaluating the Economic Significance of Downward Nominal Wage Rigidity

Michael W. Elsby

NBER Working Paper No. 12611

October 2006

JEL No. E24,E31,J30,J41

\begin{abstract}
$\underline{\text { ABSTRACT }}$
This paper formalizes and assesses empirically the implications of widely observed evidence for downward nominal wage rigidity (DNWR). It shows how a model of DNWR informed by diverse evidence for worker resistance to nominal wage cuts is nevertheless consistent with weak macroeconomic effects. This occurs because firms have an incentive to compress wage increases as well as wage cuts when DNWR binds. By neglecting potential compression of wage increases, the previous literature may have overstated the costs of DNWR to firms. Using a broad range of micro--data from the US and Great Britain I find that firms do indeed compress wage increases as well as wage cuts at times when DNWR binds. Accounting for this reduces the estimated increase in aggregate wage growth due to DNWR to be much closer to zero, consistent with the predictions of the model. These results suggest that DNWR may not provide a strong argument against the targeting of low inflation rates, as practiced by many monetary authorities. Importantly, though, this result is nevertheless consistent with evidence that suggests workers are averse to nominal wage cuts.
\end{abstract}

Michael W. Elsby

University of Michigan

Department of Economics

238 Lorch Hall

611 Tappan Street

Ann Arbor, MI 48109-1220

and NBER

elsby@umich.edu 


\section{Introduction}

A key stylized fact of modern economies is the apparent downward rigidity of nominal wages at the individual level. A burgeoning literature has detailed striking features of the distribution of nominal wage growth using micro-data. One of the most prominent features in these data is a large mass point at zero nominal wage change. In addition, there are very few nominal wage cuts relative to the number of nominal wage increases. Taken together, these facts strongly suggest the presence of downward nominal wage rigidity (henceforth DNWR). Such evidence has been found in many datasets covering many economies (for surveys see Kramarz, 2001, and Dickens et al., 2006).

Remarkably, this evidence dovetails with at least two other independent literatures in economics. The first literature conducts surveys of wage-setters and negotiators to analyze their wage setting behavior (see Bewley, 1999, and the survey in Howitt, 2002). Many of the respondents say that they are reluctant to cut the nominal wages of workers. In particular, by interviewing over 300 managers, pay professionals, labor leaders etc., Bewley finds that the most common explanation provided for this reluctance is the belief that nominal wage cuts damage worker morale, and that morale is a key determinant of worker productivity.

The second related literature presents additional evidence that people are averse to nominal losses in an array of different economic settings (Shafir, Diamond \& Tversky, 1997). A typical finding is that respondents feel that it is much more acceptable to receive a $5 \%$ nominal wage increase when inflation is $12 \%$, than a $7 \%$ wage cut when there is no inflation (Kahneman, Knetsch \& Thaler, 1986). Similar sentiments are corroborated by Genesove \& Mayer (2001) who find evidence from real-estate data that condominium owners were reluctant to sell at a nominal price below that they originally paid, even though they were typically moving locally, and hence were buying in the same market.

Such evidence is all the more remarkable as economists have long speculated that DNWR is fundamental to the workings of the macro-economy (Keynes, 1936; Tobin, 1972). In particular, it has been claimed that DNWR implies the existence of a greater Phillips curve trade-off at low rates of inflation (Akerlof, Dickens \& Perry, 1996). The intuition underlying these claims is quite 
compelling. Low inflation implies that reductions in real labor costs can only be effected through nominal wage cuts. If firms are prevented from cutting nominal wages, then their only recourse is to layoff workers, leading to increased unemployment. Thus, when inflation is low, increased inflation can relax the constraint of DNWR on wage-setting for a significant fraction of firms, and thereby reduce unemployment. This result has been of particular interest in recent years due to the adoption of inflation targeting by many monetary authorities as it implies that implementing a low inflation target could result in a persistent increase in unemployment.

In contrast to the micro-level evidence, empirical support for the macroeconomic effects of DNWR has been relatively scant. A typical reference is the analysis of Card \& Hyslop (1997) for the US. Their micro-level analysis finds strong evidence that nominal wage cuts are restricted when inflation is low, and they conclude that the existence of DNWR leads to an increase in average real wage growth of up to $1 \%$ per annum. Card \& Hyslop then assess whether the predictions of this micro-level evidence are corroborated by aggregate data. In contrast to their micro-level results, Card \& Hyslop's state-level results are much weaker. While they find some evidence for the existence of a Phillips curve trade-off, they obtain estimates that are too imprecise to conclude that this trade-off is stronger in periods of low inflation. ${ }^{1}$ This presents a puzzle: if the micro-level evidence for DNWR is so robust, why is the macro-level evidence so unpersuasive?

One potential explanation might be that wages do not play an allocative role in the labor market (Barro, 1977). In theory, wages could remain rigid for long periods of time without violating efficiency because rents exist to the continuation of a worker-firm match. When it becomes profitable for a firm to replace an incumbent worker at the current wage, the wage will be negotiated downward to the extent that the match remains efficient. Thus wage rigidity is consistent with efficiency.

In this paper I show how a model of DNWR in which the wage is allocative is nevertheless consistent with relatively weak unemployment effects of low inflation. Based on the evidence cited above, the model assumes that wage rigidity arises due to an aversion to nominal wage cuts on the

\footnotetext{
${ }^{1}$ Weak macroeconomic effects have also been found by Lebow, Saks \& Wilson (1999) for the US, and by Nickell \& Quintini (2003) and Smith (2004) for the UK. Indeed, Lebow, Saks \& Wilson coined the term "micro-macro puzzle" for the observed tension between micro- and macro-level estimates.
} 
part of the workers. ${ }^{2}$ The key insight in the analysis is that nominal wage increases in this setting are partially irreversible. Consider a firm that raises the wage today, but reverses its decision by cutting the wage by an equal amount tomorrow. When workers resist wage cuts, the net effect on productivity will be negative: today's wage increase will raise productivity, but tomorrow's wage cut will reduce productivity by a greater amount. Thus, reversals of wage increases are costly to firms. In this sense we can think of there being an asymmetric adjustment cost to changing nominal wages. $^{3}$

This insight equips us with a fundamental prediction: firms will compress wage increases as well as wage cuts in the presence of DNWR. This occurs through two channels. First, forward-looking firms temper wage increases as a precaution against future costly wage cuts. Raising the wage today increases the likelihood of having to cut the wage, at a cost, in the future. Second, even in the absence of forward-looking behavior, DNWR raises the level of lagged wages in the economy, so firms do not have to raise wages as often or as much to obtain their desired wage level. These properties of the model imply the perhaps surprising prediction that worker resistance to wage cuts should have no effect on aggregate wage growth.

These results have important implications for the previous empirical literature on DNWR. This literature has assumed (implicitly or otherwise) that the existence of DNWR has no effect on the upper tail of the wage change distribution. In particular, this is a key identifying assumption in Card \& Hyslop (1997), and leads them to use the observed upper tail of the distribution of wage changes to infer the properties of the lower tail in the absence of DNWR. The above prediction that wage increases will be compressed indicates that this assumption may be misguided. ${ }^{4}$ By

\footnotetext{
${ }^{2}$ Given the empirical evidence for worker resistance to wage cuts, it is surprising that there has not yet been an explicit model of such wage rigidity in the literature. The need for an explicit model of wage-setting in the presence of worker resistance to wage cuts has been noted in the literature: Shafir, Diamond \& Tversky (1997), p.371 write "Plausibly, the relationship [between wages and effort] is not continuous: there is a discontinuity coming from nominal wage cuts... A central issue is how to model such a discontinuity." This sentiment is echoed more recently by Altonji \& Devereux (2000), p.423 note 7 who write "[I]t is surprising to us that there is no rigorous treatment in the literature of how forward looking firms should set wages when it is costly to cut nominal wages."

${ }^{3}$ Models of adjustment costs have been widely studied in the investment and labor demand literatures, typically in the form of continuous time Brownian models (Bentolila \& Bertola, 1990, and Abel \& Eberly, 1996, are closest in spirit to the model analyzed here). In contrast, we formulate and solve our model of partial irreversibility in discrete time. This is helpful for two reasons. First, since data are reported in discrete intervals, this method allows us to align theoretical and empirical concepts more naturally. Moreover, many wage contracts are renegotiated on an annual basis, which is more consistent with a discrete-time setup.

${ }^{4}$ This is not to say that Card \& Hyslop (1997) is any more subject to this criticism than other previous empirical
} 
neglecting the compression of wage increases, previous empirical research may have overstated the increase in aggregate wage growth due to DNWR, and thereby the costs of DNWR to firms.

I seek evidence for these predictions using micro-data for the US and Great Britain. I find significant evidence that the upper tail of the wage change distribution exhibits a compression of wage increases related to DNWR. In particular, I find that this limits the estimated increase in aggregate real wage growth due to DNWR from around $1-1.5 \%$ to no more than $0.3 \%$. This is because firms can "save" at least $75 \%$ of the increase in wage growth due to restricted wage cuts by reducing nominal wage increases.

As an additional test of the implications of worker resistance to wage cuts, I show that the model also implies that increased rates of turnover should mitigate the necessity for firms to restrict wage increases. This occurs because higher turnover reduces the probability that a given worker will stay in the firm an additional period, and thus renders the firm more myopic when it sets wages. Thus firms do not need to compress wage increases as a precaution against future costly wage cuts to the same extent. I find evidence for this hypothesis using data from Great Britain. This reinforces the claim that a model of DNWR based on worker resistance to nominal wage cuts is a useful way of understanding the empirical properties of wage setting.

Based on this evidence, I conclude that there is no reason to expect the macro effects of DNWR to be as large as previously envisaged, and therefore that it does not provide a strong argument against the adoption of a low inflation target. Importantly, however, this result is nevertheless consistent with the diverse body of evidence that suggests workers resist nominal wages cuts.

The rest of the paper is organized as follows. Section 2 presents an explicit behavioral model of wage-setting in the presence of worker resistance to nominal wage cuts; section 3 fleshes out some of the predictions of these models that can be taken to the data; section 4 presents the empirical methodology and the results obtained; section 5 concludes. Where possible, I omit technical details from the main text, and relegate them to the appendices ${ }^{5}$.

work on DNWR. Rather, it is the clarity of the identifying assumptions in that paper that allows a particularly clean point of contrast with the implications of the model and results of this paper.

${ }^{5}$ In addition, we omit some of the more straightforward proofs to save space - these are available from the author on request. 


\section{A Model of DNWR based on Worker Resistance to Wage Cuts}

In this section I present an explicit model of downward nominal wage rigidity based on the observations detailed in the empirical literatures mentioned above. In particular, I study the optimal nominal wage policies of worker-firm pairs for whom the productivity of the worker (denoted $e$ ) depends upon the wage as follows:

$$
e=\ln \left(\frac{\omega}{b}\right)+c \ln \left(\frac{W}{W_{-1}}\right) \mathbf{1}^{-}
$$

where $W$ is the nominal wage, $W_{-1}$ the lagged nominal wage, $\mathbf{1}^{-}$an indicator for a nominal wage cut, $\omega \equiv W / P$ the real wage, and $b$ a measure of real unemployment benefits (which I assume to be constant over time). The parameter $c>0$ varies the productivity cost to the firm of a nominal wage cut.

The motivation for the qualitative features of this effort function is as follows ${ }^{6}$. I assume that worker effort depends positively on the difference between the level of the real wage, $\omega$, and real unemployment benefits, $b$. This captures the idea that, the higher the worker's real standard of living from being in work relative to unemployment, the harder that worker will work. In addition, I model the productivity loss due to nominal wage cuts by assuming that effort is falling in the geometric nominal wage cut. The reasoning for this is that the most obvious alternative - that it is the absolute value of the cut in the nominal wage that reduces effort - is implausible in the following sense. It implies that a wage cut of a cent will cause the same loss in effort whether last period's nominal wage is $\$ 1$ or $\$ 1,000,000$. This is clearly extreme, so I employ the more sensible concept that it is the percentage cut in the nominal wage that affects effort ${ }^{7}$.

The qualitative features of this effort function are illustrated in Figure 1. Clearly, there is a

\footnotetext{
${ }^{6}$ The precise parametric form of (1) is chosen primarily for analytical convenience. None of the qualitative results emphasized in what follows depends on the specific parametric form of (1) - the key is that effort is increasing in the wage and kinked around the lagged nominal wage.

${ }^{7}$ One may be interested in a specification with a fixed effort cost due to wage cuts, or a more general convexity of effort in wage cuts informed by the literature on loss aversion (Kahneman \& Tversky, 1979). Both such specifications would lead employers to cut the wage dramatically if they cut the wage at all. This differs from the model analyzed here in that we would expect to see a "hole" in the density of wage changes to the left of zero. Whilst previous studies have not found strong support for this (Card \& Hyslop, 1997), further work may be worthwhile to assess this more formally.
} 
kink at $W=W_{-1}$ reflecting the existence of DNWR. In particular, the marginal productivity loss of a nominal wage cut exceeds the marginal productivity gain of a nominal wage increase:

$$
\frac{\partial e /\left.\partial W\right|_{W \uparrow W_{-1}}}{\partial e /\left.\partial W\right|_{W \downarrow W_{-1}}}=1+c>1
$$

This characteristic is what makes nominal wage increases (partially) irreversible - a nominal wage increase can only be reversed at an additional marginal cost of $c$. Clearly, this is the key driving force in the model that I seek to analyze, and the parameter $c$ is what drives this feature of the model.

The effort function, (1), can be interpreted as a very simple way of capturing the basic essence of the motivations for DNWR mentioned in the literature. It is essentially a parametric form of effort functions in the spirit of the fair-wage effort hypothesis expounded by Solow (1979) and Akerlof \& Yellen (1988), with an additional term reflecting the impact of nominal wage cuts on effort - as envisaged in the evidence cited in the introduction. Bewley (1999) also advocates such a characterization ${ }^{8}$ :

"The only one of the many theories of wage rigidity that seems reasonable is the morale theory of Solow..." Bewley (1999), p.423.

"The [Solow] theory...errs to the extent that it attaches importance to wage levels rather than to the negative impact of wage cuts." Bewley (1999), p.415.

In addition, an effort function with these properties can be derived from a compensating differentials model where worker utility exhibits nominal loss aversion. The basic intuition for this is that, if workers dislike nominal losses and the firm wishes to cut the nominal wage, then the firm must compensate the worker in the form of lower on-the-job effort in order to prevent the worker from quitting. Thus, in this sense, (1) can be considered a reduced form of a model in which workers dislike nominal loss. The goal of this paper is not to highlight the nuances of emphasis - which do

\footnotetext{
${ }^{8}$ However, such is the intricacy of Bewley's study, he would probably consider (1) a simplification, not least for its neglect of emphasis on morale as distinct from productivity, and of the internal wage structure of firms as a source of wage rigidity. We argue that it is a useful simplification as it provides key qualitative insights into the implied dynamics of wage-setting under more nuanced theories of morale.
} 
indeed exist - between these behavioral foundations, but rather to show that they share a common, theoretically important, qualitative implication as to the nature of a firm's wage-setting choice. This is intended as a start towards richer models of these phenomena, and to this end aims to unify rather than to differentiate.

The most comparable previous attempt at explicitly modelling the behavioral foundation to DNWR is that of Akerlof, Dickens \& Perry (1996). However, Akerlof et al. present a model in which firms have no operational discretion over wage-setting - wages are given by a wage-setting relationship which firms take as exogenous, and which dictates that nominal wages can never fall. Thus, the implicit assumption in their model is that firms do not cut wages because, if they did, all of their workers would quit. The model presented in this paper differs critically in that firms have a non-trivial wage-setting decision: firms can cut nominal wages if they wish, but it will have a strong adverse effect on productivity at the margin. I argue that this is a more desirable setup. In the first instance, it accords better with the evidence that firms restrict wage cuts due to concerns over morale within the firm, rather than because the external labor market dictates it (Bewley, 1999). Secondly, I will show that a model with wage discretion captures an important characteristic of the available data: that wage increases are also compressed when DNWR binds.

\section{The Wage Setting Problem}

I consider a discrete-time, infinite-horizon model in which price-taking worker-firm pairs choose the nominal wage $W_{t}$ at each date $t$ to maximize the expected discounted value of profits. For simplicity, I assume that each worker-firm's production function is given by $a \cdot e$, where $a$ is a real technology shock that is idiosyncratic to the worker-firm match, is observed contemporaneously, and acts as the source of uncertainty in the model. Thus, defining $\beta \in[0,1)$ as the discount factor of the firm, the typical firm's decision problem is given by:

$$
\begin{array}{cl}
\max _{\left\{W_{t}\right\}} & E_{t}\left[\sum_{s=t}^{\infty} \beta^{s-t}\left\{a_{s} e_{s}-\omega_{s}\right\}\right] \\
\text { where } & e_{s}=\ln \left(\frac{\omega_{s}}{b}\right)+c \ln \left(\frac{W_{s}}{W_{s-1}}\right) \mathbf{1}_{s}^{-}
\end{array}
$$


It turns out in what follows that it is convenient to re-express the firm's profit stream in constant date $t$ prices. To this end, I multiply through by $P_{t}$, which I define as the competitive price level at date $t$, and assume that it evolves according to $P_{t}=(1+\pi) P_{t-1}$, where $\pi$ is the rate of inflation. Finally, defining the nominal counterparts, $A_{t} \equiv P_{t} a_{t}$ and $B_{t} \equiv P_{t} b$ and substituting for $e_{t}$, I obtain the following optimization problem for the firm:

$$
\max _{\left\{W_{t}\right\}} E_{t}\left[\sum_{s=t}^{\infty}\left(\frac{\beta}{1+\pi}\right)^{s-t}\left\{A_{s}\left[\ln \left(\frac{W_{s}}{B_{s}}\right)+c \ln \left(\frac{W_{s}}{W_{s-1}}\right) \mathbf{1}_{s}^{-}\right]-W_{s}\right\}\right]
$$

I assume that the nominal shock has support $[0, \infty)$ and that its evolution can be described by the cumulative density function $F\left(A^{\prime} \mid A\right)$. Thus, rewriting the problem in recursive form ${ }^{9} \mathrm{I}$ have ${ }^{10}$ :

$$
v\left(W_{-1}, A\right)=\max _{W}\left\{A\left[\ln \left(\frac{W}{B}\right)+c \ln \left(\frac{W}{W_{-1}}\right) \mathbf{1}^{-}\right]-W+\frac{\beta}{1+\pi} \int v\left(W, A^{\prime}\right) d F\left(A^{\prime} \mid A\right)\right\}
$$

(5) is the basic problem that I will attempt to solve in what follows ${ }^{11}$.

\subsection{Some Intuition for the Model}

To anticipate the model's results, in this section I present the economic intuition for each of the predictions of the model. First, the model predicts that there will be a spike at zero in the distribution of nominal wage changes across firms. This occurs because of the kink in the objective function at $W=W_{-1}$. In particular, this implies that for each firm there will be a range of values ("region of inaction") for the nominal shock, $A$, for which it is optimal not to change the nominal wage. Since $A$ is distributed across firms, there will exist a positive fraction of firms each period whose realization of $A$ lies in their region of inaction that will in turn not change their nominal wage.

\footnotetext{
${ }^{9}$ We adopt the convention of denoting lagged values by a subscript, -1 , and forward values by a prime, '.

${ }^{10}$ In addition, we make the assumptions that the measure $d F\left(A^{\prime} \mid A\right)$ satisfies the Feller property and is monotone, so that the mapping (5) preserves continuity of the value function, and monotonicity of the value function in $A$. A sufficient condition for this is that $A$ is governed by the stochastic difference equation, $A^{\prime}=g\left(A, \varepsilon^{\prime}\right)$, where $g$ is a continuous function, $\varepsilon^{\prime}$ is an i.i.d. innovation (see Stokey \& Lucas, 1989, pp.237, 261-262), and $g_{A}>0$. We maintain these assumptions throughout the paper.

${ }^{11}$ There is an issue that, for sufficiently low values of the wage, effort is potentially negative. However, accounting for such a non-negativity constraint significantly complicates the solution to the model without much gain in relevance. We maintain the assumption that the level of benefits is sufficiently low relative to wages as to allow almost all firms to ignore this constraint.
} 
Second, in the event that a firm does decide to change the nominal wage, the wage change will be actively compressed relative to the case where there is no DNWR. That nominal wage cuts are attenuated is straightforward to explain - as wage cuts involve a discontinuous fall in productivity at the margin, the firm will be less willing to implement them. In particular, some small wage cuts that would have been implemented in the absence of DNWR will instead be implemented as wage freezes. Moreover, larger counterfactual wage cuts will be reduced in magnitude. It is slightly less obvious why nominal wage increases are also attenuated in this way. The reason is that, in an uncertain world, increasing the wage today increases the likelihood that the firm will have to cut the wage, at a cost, in the future.

A direct implication of this last prediction is that increases in the productivity cost of cutting the nominal wage, $c$, will accentuate all these effects. That is, a higher productivity cost due to nominal wage cuts will widen the region of inaction, thereby increasing the mass point at zero in the distribution of nominal wage changes, and will also render the active compression of nominal wage changes more acute.

An additional, perhaps more fundamental effect that obtains from the model even in the absence of active compression is what I will refer to as "latent compression" of wage increases. This effect captures the idea that an inability on behalf of firms to cut wages will tend to raise the wages that firms inherit from the past. As a result, when raising wages, firms do not have to increase wages by as much or as often in order to achieve their optimal wage. Thus, this process of latent compression works in tandem with the active compression of wage increases outlined above ${ }^{12}$.

The final prediction to emphasize at this stage is the effect of increased inflation on nominal wage increases. In particular, the active compression of nominal wage increases becomes less pronounced as inflation rises. As explained earlier, this is because the only reason firms restrict wage increases in the model is the prospect of costly nominal wage cuts in the future. Since higher inflation reduces the probability of this occurring, firms no longer need to worry as much about

\footnotetext{
${ }^{12}$ Identifying this additional effect is an important benefit of the infinite horizon model studied here. In particular, one might imagine that active compression-type results could be obtained from a "simpler" two-period model. Latent compression will be shown to be an outcome of steady state considerations, which cannot be treated in a two-period context.
} 
increasing the nominal wage. ${ }^{13}$

\subsection{The Dynamic Model}

The basic structure of the solution to the full dynamic model, (5), is as follows. I solve the problem by first taking the first-order condition with respect to $W$, conditional on $\Delta W \neq 0$ :

$$
\left(1+c \mathbf{1}^{-}\right) \frac{A}{W}-1+\frac{\beta}{1+\pi} D(W, A)=0, \quad \text { if } \Delta W \neq 0
$$

where $D(W, A) \equiv \int v_{W}\left(W, A^{\prime}\right) d F\left(A^{\prime} \mid A\right)$ is the marginal effect of the current wage choice on the future profits of the firm. Clearly, a key step in solving for the firm's optimal wage policy involves characterizing the properties of the function $D(\cdot)$. For the moment, however, note first that the general structure of the optimal nominal wage policy is as follows:

Proposition 1 The optimal nominal wage policy in the dynamic model is of the form:

$$
\begin{array}{ccccc}
\text { If } & A>u\left(W_{-1}\right) \equiv A_{u}, & \Delta W>0 & \text { until } & W=u^{-1}(A) \\
\text { If } & A<l\left(W_{-1}\right) \equiv A_{l}, & \Delta W<0 & \text { until } & W=l^{-1}(A) \\
\text { If } & A \in\left[A_{l}, A_{u}\right], & \Delta W=0 & \text { or } & W=W_{-1}
\end{array}
$$

where the functions $u(\cdot)$ and $l(\cdot)$ satisfy:

$$
\begin{aligned}
\frac{u(W)}{W}-1+\frac{\beta}{1+\pi} D(W, u(W)) & \equiv 0 \\
(1+c) \frac{l(W)}{W}-1+\frac{\beta}{1+\pi} D(W, l(W)) & \equiv 0
\end{aligned}
$$

The reasoning for this is very straightforward. Proposition 1 uses the conditional first-order condition (6) to define the functions $u(\cdot)$ and $l(\cdot)$, as in (8). These functions determine the optimal

\footnotetext{
${ }^{13}$ One might think that a standard model of menu costs predicts a compression of wage increases in times of low inflation. Intuitively, as firms increase prices less often to avoid successive payment of menu costs in high inflation environments, when they do increase the price, they will increase it by a greater amount. However, if this were the correct model, one would expect to see "holes" either side of zero in the density of nominal wage changes, and moreover that these holes would widen as inflation rises. Whilst previous empirical work has found some evidence for menu cost effects, these effects have only a modest impact on wage changes around zero (Card \& Hyslop, 1997), and certainly are not accentuated in times of high inflation.
} 
relationship between the nominal wage, $W$, and the nominal shock, $A$, in the event that wages are adjusted up or down respectively. The rest of the result follows from the fact that, by virtue of the continuity and concavity of the firm's objective, (5), the optimal value of $W$ must be a continuous function of $A^{14}$.

However, to complete the characterization of the firm's optimal nominal wage policy, it is necessary to establish the functions $u(\cdot)$, and $l(\cdot)$. In particular, it can be seen from (8) that, in order to solve for these functions, one requires knowledge of the functions $D(W, u(W))$ and $D(W, l(W))$. This is aided by Proposition 2:

Proposition 2 The function $D(\cdot)$ satisfies:

$$
D(W, A)=\int_{l(W)}^{u(W)}\left[\frac{A^{\prime}}{W}-1\right] d F-\int_{0}^{l(W)} c \frac{A^{\prime}}{W} d F+\frac{\beta}{1+\pi} \int_{l(W)}^{u(W)} D\left(W, A^{\prime}\right) d F
$$

which is a contraction mapping in $D(\cdot)$ over the relevant range, and thus has a unique fixed point over this range.

The intuition for this result is as follows. The first term on the RHS of (9) represents tomorrow's expected within-period marginal benefit, given that $W^{\prime}$ is set equal to $W$. To see this, note that the firm will freeze tomorrow's wage if $A^{\prime} \in\left[A_{l}^{\prime} \equiv l(W), A_{u}^{\prime} \equiv u(W)\right]$, and that in this event a wage level of $W$ today will generate a within-period marginal benefit of $\left[\frac{A^{\prime}}{W}-1\right]$. Similarly, the second term on the RHS of (9) represents tomorrow's expected marginal cost, given that the firm cuts the nominal wage tomorrow. Finally, the last term on the RHS of (9) accounts for the fact that, in the event that tomorrow's wage is frozen, the marginal effects of $W$ persist into the future in a recursive fashion. It is this recursive property that provides the key to determining the function $D(\cdot)$.

\footnotetext{
${ }^{14}$ This follows from the Theorem of the Maximum (see e.g. Stokey \& Lucas, 1989, pp. 62-63).
} 
For the purposes of the present paper, a specific form for $F(\cdot)$ is used. In particular, imagine that real shocks, $a$, evolve according to the following geometric random walk:

$$
\begin{aligned}
\ln a^{\prime} & =\ln a-\frac{1}{2} \sigma^{2}+\varepsilon^{\prime} \\
\varepsilon^{\prime} & \sim \mathcal{N}\left(0, \sigma^{2}\right)
\end{aligned}
$$

Given that prices are assumed to evolve according to $P^{\prime}=(1+\pi) P$, this yields the following process for nominal shocks, $A$ :

$$
\ln A^{\prime}=\ln (1+\pi)+\ln A-\frac{1}{2} \sigma^{2}+\varepsilon^{\prime}
$$

Note that this implies that $E\left(A^{\prime} \mid A\right)=(1+\pi) A$. I then use this information to determine the full solution as follows. First, I solve for the functions $D(W, u(W))$ and $D(W, l(W))$ using equation (9), via the method of undetermined coefficients. Then, given these, I obtain the solutions for $u(W)$ and $l(W)$ using the equations in (8). Following this method yields Proposition 3:

Proposition 3 If nominal shocks evolve according to the geometric random walk, (11), the functions $u(\cdot)$ and $l(\cdot)$ are of the form:

$$
\begin{aligned}
& u(W)=u \cdot W \\
& l(W)=l \cdot W
\end{aligned}
$$

where $u$ and $l$ are given constants that depend upon the parameters of the model, $\{c, \beta, \pi, \sigma\}$.

Thus, the optimal nominal wage policy takes the following piecewise linear form:

$$
\begin{aligned}
& \text { If } \quad A>u \cdot W_{-1} \equiv A_{u}, \quad \Delta W>0 \quad \text { until } \quad W=A / u \\
& \text { If } \quad A<l \cdot W_{-1} \equiv A_{l}, \quad \Delta W<0 \quad \text { until } \quad W=A / l \\
& \text { If } \quad A \in\left[A_{l}, A_{u}\right], \quad \Delta W=0 \quad \text { or } \quad W=W_{-1}
\end{aligned}
$$




\subsection{Some Special Cases}

In order to get a feeling for how the model works, this section presents solutions to special cases of the above full dynamic model. In particular, I consider two cases: where nominal wage increases are fully reversible $(c=0)$, and the case where nominal increases are partially irreversible $(c>0)$, but where firms are myopic $(\beta=0)$.

\section{The Case where $c=0$}

Note that the assumption that $c=0$ removes any dynamic considerations from the firm's wagesetting choice by removing the dependence of effort on last period's wage. In this case, it is straightforward to show that the solution for this problem is:

$$
W=A \quad \Longrightarrow \quad \Delta W=\Delta A
$$

In this case, wage changes fully reflect changes in productivity, and the distribution of nominal wage changes across firms will be exactly the same as the distribution of changes in the nominal shock. I term this result the counterfactual solution.

The Case where $\beta=0$

This is another static special case of (5), but retains the productivity cost of cutting the nominal wage, $c$. In this case it is straightforward to confirm that the optimal wage policy is the special case of (13) where $u=1$ and $l=\frac{1}{1+c}$. By comparing this wage policy to the case where $c=0$, one can see that the firm is taking counterfactual nominal wage cuts in the interval $\left[\frac{W_{-1}}{1+c}, W_{-1}\right]$ and is instead implementing them as wage freezes. Moreover, for all counterfactual wages below $\frac{W_{-1}}{1+c}$, the firm is reducing the magnitude of wage cuts by a factor $\frac{1}{1+c}$. Thus nominal wage cuts are being actively compressed as a result of DNWR.

However, the same is not true for nominal wage increases. All counterfactual wage increases are being implemented without alteration. The reason for this is that $\beta=0$ implies that the firm doesn't care about the future consequences of raising the nominal wage in the current period. This will be shown to be in stark contrast to the general case where $\beta>0$ in the following section. 
However, it should be noted at this point that even in this simple case the methods of previous empirical studies will be potentially biased. Whilst this special case yields no active compression of wage increases by firms, there will still be some latent compression: since DNWR places upward pressure on the level of wages in the past, the firm does not have to raise wages as frequently to achieve their target wage today.

\section{Predictions}

\subsection{Active Compression}

Returning to the more general solution in (13), it can be seen that active compression of wage changes can be related to the parameters $u$ and $l$. Numerical simulations of the model establish that $u>1>l$ and that $1 / l>u .^{15}$ This is precisely in accordance with the intuition in section 2.1. Since $u>l$ there exists a region of inaction for the nominal shock variable in which it is optimal not to change the nominal wage. Moreover, because $l<1$ there will be an active compression of nominal wage cuts. This follows directly from the discontinuous fall in effort following a wage cut at the margin. In addition, $u>1$ means that nominal wage increases will also be actively compressed relative to the counterfactual solution. Recall that the intuition for this is that raising the nominal wage today raises the likelihood that the firm will wish to cut the wage, at a cost, in the future. Finally, the fact that $1 / l>u$ implies that the active compression of wage increases will not be as strong as that for wage cuts. The reason for this is that the potential costs associated with wage increases are discounted in two ways. First, some discounting derives from the fact that raising the wage may only increase the costs of wage cuts in the future. But, in addition to this, the probability that these additional future costs will be realized is less than one, leading to further discounting.

Recall that a key concern is with the characteristics of the nominal wage change distribution. Using (13) it is straightforward to establish the following result on the form of the log nominal wage change distribution, conditional on the lagged wage:

\footnotetext{
${ }^{15}$ Unfortunately, due to the analytical complexity of the solution, a formal proof of this result has proved elusive.
} 
Proposition 4 The log nominal wage change density, conditional on the lagged wage, implied by the model of section 2 is given by:

$$
f\left(\Delta \ln W \mid W_{-1}\right)= \begin{cases}\tilde{f}\left(\Delta \ln W+\ln u \mid W_{-1}\right) & \text { if } \Delta \ln W>0 \\ \tilde{F}\left(\ln u \mid W_{-1}\right)-\tilde{F}\left(\ln l \mid W_{-1}\right) & \text { if } \Delta \ln W=0 \\ \tilde{f}\left(\Delta \ln W+\ln l \mid W_{-1}\right) & \text { if } \Delta \ln W<0\end{cases}
$$

where $\tilde{F}\left(\cdot \mid W_{-1}\right)$ and $\tilde{f}\left(\cdot \mid W_{-1}\right)$ are the c.d.f. and p.d.f. of the counterfactual (no DNWR) conditional log nominal wage change distribution.

Figure 2 illustrates this result. In particular, it shows that the distribution of log wage cuts is exactly the same as the counterfactual distribution below $\ln l<0$, just shifted horizontally by an amount $-\ln l>0$. A symmetric result obtains for wage increases. The residual density is "piled up" to a mass point at zero wage change. Thus, the effect of worker resistance to wage cuts is to yield a conditional log wage change distribution with dual censoring from above and below relative to the counterfactual ${ }^{16}$.

The key prediction that will be tested in the following empirical work is the effect of the rate of inflation, $\pi$, on the compression of nominal wage increases. To this end, figure 3 presents results for the effect of changes in the rate of inflation on the parameter $u$. It is clear is that the firm will reduce any active compression of wage increases as inflation rises since $u$ falls as $\pi$ rises. The intuition for this is that active compression of wage increases occurs only insofar as wage increases raise the likelihood of future costly nominal wage cuts. To see this, note that the special case in which the firm does not care about the future $(\beta=0)$ yielded no active compression of wage increases $(u=1)$. Thus, since higher inflation reduces the likelihood of future costly nominal cuts, the firm no longer needs to worry about raising the nominal wage today. A key related result is that as inflation becomes large, $u \rightarrow 1$. That is, high inflation implies that wage increases cease to be actively compressed relative to a counterfactual world without DNWR. Thus, if the model of section 2 is correct, one would expect to observe the upper tail of $f\left(\Delta \ln W \mid W_{-1}\right)$ becoming more

\footnotetext{
${ }^{16}$ This censoring result has interesting parallels in the previous empirical literature. Altonji \& Devereux (2000) estimate an econometric model similar to (15) except that they do not account for the possibility of compression of wage increases.
} 
dispersed as inflation rises. This is illustrated in Figure 4. However, this is not the end of the story: the next section shows that there are additional reasons for there to be a compression of wage increases, even in the absence of these effects.

\subsection{Latent Compression}

All of the above discussion on active compression has been in terms of the nominal wage change distribution conditional on the lagged nominal wage. The reason for this is that the lagged wage is taken as given (is part of the state) at the time of setting the current wage, and so all theories will yield direct implications on the conditional distribution, $f\left(\Delta \ln W \mid W_{-1}\right)$. However, most of the previous empirical literature has concentrated on the properties of the unconditional distribution, $f(\Delta \ln W)$, typically by estimating some measure of the increase in average wage growth due to DNWR, $E(\Delta \ln W \mid D N W R)-E(\Delta \ln W \mid n o D N W R)$, to try to gain an impression of the effect of DNWR on the firms' real labor costs. The following proposition demonstrates that this emphasis in the previous literature may well be misleading:

Proposition 5 DNWR has no effect on average wage growth in the long run for finite $G \equiv u / l$.

This result can be interpreted in a number of ways. First, and closest to the form of the proof, note that the optimal wage policy (13) implies that the difference in the levels of the log wage with and without DNWR must be bounded (between $-\ln u<0$ and $-\ln l>0$ ). Thus, it follows that the rates of growth of actual and counterfactual log wages cannot be different in the long run, as it would necessarily imply a violation of these bounds. ${ }^{17}$

An alternative interpretation for this result is that it is simply a requirement for the existence of a steady state in which average growth rates are equal. Since productivity shocks grow on average at a constant rate, so must wages grow at that same rate in the long run. Thus, even the model with DNWR must comply with this simple steady state condition in the long run.

How might this result come about? First, the results above indicate that firms may actively compress wage increases as a precaution against future costly wage cuts, thereby limiting the wage

\footnotetext{
${ }^{17}$ A similar result has been established independently in the investment literature by Bloom (2000).
} 
growth increasing effects of DNWR. However, this cannot be the whole story - we saw above that the active compression of wage increases will be less than that of wage cuts. In addition, consider the case where $\beta=0$. Recall that this is the case in which there is no active compression of wage increases as firms are myopic. Figure 5 shows a simulation of the unconditional wage change distribution implied by the behavioral model in this case. It can be seen from Figure 5 that, contrary to the assumption of previous studies, the upper tail of $f(\Delta \ln W)$ displays a compression in the presence of DNWR. Thus, the upper tail of the wage change distribution is still compressed, even if firms do not actively compress wage increases.

This provides an additional insight into the process by which this steady state requirement might be achieved in practice. If wage increases are not actively compressed, this means that when firms increase the wage, they increase it to the counterfactual level, $A$. However, recall that the existence of DNWR will tend to raise the general level of lagged wages in the economy, as firms will have been constrained in cutting wages in the past. Thus, when firms increase the wage, they do not have to increase it by as much or as often to reach the counterfactual wage level. Thus the upper tail of $f(\Delta \ln W)$ will indeed still be affected by the existence of DNWR - in particular, it will be less dispersed, as seen in Figure 5. I term this additional effect "latent compression".

\subsection{The Costs of DNWR to Firms}

Proposition 5 has important implications with respect to the previous empirical literature. First, by not taking into account the compression of wage increases, previous empirical studies could have overstated the increase in wage growth due to DNWR. To see this, consider Figure 6. This shows three simulated wage change distributions derived from the model of section 2 . The bold line shows the wage change distribution with DNWR $(c>0)$, whereas the thick dashed line illustrates the true counterfactual wage change density $(c=0)$. In addition, I include a "median symmetric" (hereafter MS) counterfactual density that is derived by imposing symmetry in the upper tail of the distribution with DNWR (according to the method of Card \& Hyslop, 1997). It can be clearly seen that, by using the MS counterfactual, we obtain an overestimate of the increase in average wage growth due to DNWR when there is a compression of the upper tail. By neglecting this 
compression, previous studies could have overstated the effects of DNWR on average wage growth.

The question then arises as to how this bias is related to the implied costs of DNWR to firms. Proposition 6 addresses this issue:

Proposition 6 To a first-order approximation around the frictionless $(c=0)$ case,

1. the true reduction in the value of a firm due to $D N W R$ is equal to $-g \cdot E(\Delta \ln A \mid \Delta \ln A<0)$. $A C L^{*}$ and is entirely driven by reductions in effort following wage cuts; and

2. assuming a MS counterfactual implies an overstatement of the increase in the value of labor costs equal to $g \cdot \frac{\beta}{1-\beta} \cdot A C L^{*}$;

where $g$ is the increase in average wage growth due to DNWR assuming a MS counterfactual, and $A C L^{*}$ is the average value of real labor costs.

A number of points are worthy of note in the light of this. First, a corollary of Proposition 6 is that the conventional view that DNWR imposes costs on firms by increasing firms' real labor costs is incorrect in this model. The true impact of DNWR to firms (part 1 of Proposition 6) occurs because nominal wage cuts substantially reduce worker effort at the margin, and thereby reduce productivity. In this way, Proposition 6 fundamentally alters the way one should think about the costs imposed on firms from being constrained in their ability to cut wages.

Moreover, Proposition 6 also allows us to compare the magnitude of the overstatement of the costs of DNWR under the MS method relative to the true costs of DNWR implied by the current model. As an example, if $g=.01$ and $E(\Delta \ln A \mid \Delta \ln A<0)=.15^{18}$, Proposition 6 suggests that the true costs of DNWR are approximately $0.15 \%$ of the average value of labor costs. In contrast, taking $\beta=.6$ as an example, the MS method would imply additional costs of around $1.5 \%$ of labor costs, a ten-fold overstatement. More generally, the ratio of these is given by $-\frac{\beta}{1-\beta}[E(\Delta \ln A \mid \Delta \ln A<0)]^{-1}$. Figure 7 plots this ratio as a function of $\beta$, the firm's discount factor. It can be seen that for even mildly forward-looking firms the implied overstatement is

\footnotetext{
${ }^{18}$ Card \& Hyslop $(1997)$ conclude on an estimate of $g \approx .01$. The value $E(\Delta \ln A \mid \Delta \ln A<0)=.15$ broadly corresponds to the average real wage cut under high inflation found in the data used in section 4 .
} 
quite severe. The intuition for this is quite simple - the suggestion that DNWR raises the rate of growth of wages implies that forward-looking firms will anticipate an accumulation of increased labor costs over time, which can be large.

One might be tempted to argue that Proposition 6 nevertheless states that the true costs of DNWR are indeed dependent on $g$, the MS estimate of the increase in wage growth due to DNWR, and that therefore the MS results are informative of the costs of DNWR. However, the key point is that $g$ is informative, but not in the sense that previous studies have thought. Importantly, $g$ does not reflect the increase in wage growth due to DNWR; and if it did, it would imply much larger economic costs on firms than is truly the case.

\subsection{Turnover Effects}

In addition to the above, the model of section 2 can also provide predictions on the effect of turnover on the distribution of wage growth. To see this, imagine that there is now some exogenous probability that a worker will separate from the firm each period, $\delta<1$. The effect of this is to reduce the firm's real discount factor from $\beta$ to $\beta \delta$, since there is now a lower probability that the match will survive until next period. As a result, sectors in which turnover is high (high $\delta$ ) will act more myopically than sectors with low turnover. In other words, high turnover sectors should set wages more like the special case in which $\beta=0$ (section 2.2), and low turnover sectors should act more like the forward looking firm of section 2.3. It follows that one should expect to see a greater active compression of wage increases in sectors with lower turnover. ${ }^{19}$ Moreover, one should also expect this effect to be stronger in periods of low inflation: when inflation is high, the firm does not have to worry about the future consequences of current wage decisions, regardless of the probability that a worker will stay at the firm. I will examine these claims in the forthcoming empirical section to which I now turn.

\footnotetext{
${ }^{19}$ Thanks to Marianne Bertrand for originally suggesting this idea to me.
} 


\section{Empirical Implementation}

\subsection{Data}

The data used in this analysis are taken from the Current Population Survey (CPS) and the Panel Study of Income Dynamics (PSID) for the US, and the New Earnings Survey Panel Dataset (NESPD) for Great Britain. For all datasets, the relevant wage measure used in this study is the basic hourly wage rate for respondents aged 16 to 65 . Since the CPS and PSID are relatively well-known datasets, I only describe them briefly here.

The CPS samples are taken from the Merged Outgoing Rotation Group (MORG) files from 1979 to 2002. I link respondents across consecutive years using a method similar to that advocated by Madrian \& Lefgren $(1999)^{20}$. This method yields approximately 25,000 individual annual wage changes each year from 1980-2002, although changes in sampling method yield lower sample sizes in 1985-86 and 1995-96 (see Table 1). Unfortunately, one cannot easily differentiate between job-stayers and changers using the CPS due to a lack of information on job characteristics and tenure $^{21}$. Additional problems arise in the CPS resulting from the survey redesign in 1994. Figure 8 illustrates the dispersion of log wage changes in the CPS over the sample period, as measured by the standard deviation, and the 90-10 and 80-20 percentile differentials. One can clearly detect a significant rise in the dispersion of wage changes starting in $1994^{22}$. In the ensuing empirical analysis I attempt to control for this.

The PSID data are taken from the random (not poverty) samples for the years 1971 to 1992. I use data on regular hourly pay rates for household heads to construct individual annual wage changes. I concentrate on the wage changes of job-stayers ${ }^{23}$ by excluding workers with tenure of

\footnotetext{
${ }^{20}$ In particular, first we match individuals according to their personal identifiers, as well as their month of interview. We then employ Madrian \& Lefgren's "s $|\mathrm{r}| \mathrm{a}$ " criterion - i.e. that matched observations must report the same sex and race across years, and that the difference in their age must lie in the interval $[0,2]$.

${ }^{21}$ Card \& Hyslop (1997) attempt to identify job-stayers in the CPS by restricting their analysis to those respondents who do not change occupation year-on-year. We do not make such an attempt as it is complicated by changes in the occupational classification over the period. However, the sample used in this paper displays very similar properties to that of Card \& Hyslop.

${ }^{22}$ This is likely to be due in particular to an increase in the fraction of imputed wage observations in the CPS for 1994 onwards. However, it is difficult to simply deleted such imputed observations from the analysis due to large changes in the accuracy of the CPS imputation flags over the period - see Hirsch \& Schumacher (2004).

${ }^{23}$ It should be noted that tenure in the PSID refers to the time spent with the same employer, except for the years 1979-80 when it refers to the time spent in the same position.
} 
strictly less than 12 months $^{24}$, and additionally remove respondents who report that they live in a foreign country, and top-coded wage data. The PSID sample provides us with much smaller samples than those from the CPS, with approximately 1,300-2,200 individual wage changes each year over the sample period (see Table 1$)$.

Finally, the NESPD is an individual level panel which is collected in April of each year running from 1975 through to 2001 for Great Britain ${ }^{25}$. It is a $1 \%$ sample of British income tax-paying workers with a National Insurance (Social Security) number that ends in a given pair of digits. The wage measure used is the gross hourly earnings, excluding overtime, of job-stayers whose pay is unaffected by absence. Table 1 provides summary statistics for the NESPD sample. An important observation to make is that the statistics for the level of real wage growth in 1977 are vastly lower than in all other periods in the NESPD. In particular, the fraction of respondents reporting a real wage cut was $77.64 \%$ in 1977 , but was never below $52 \%$ in any other year in the sample period (see Table 1). The reason for this is that the UK government of the time instituted an incomes policy in order to try to curb high inflation. In particular, these policies were remarkably successful in containing wage inflation in late 1976 to early 1977 as a result of the cooperation of the unions (see Cairncross, 1995, pp. 220-221). Despite this, however, retail price inflation remained high, thereby leading to the significant real wage losses that I observe in the data. As a result of this, I treat the 1977 data as an outlier throughout the rest of the analysis.

Since the descriptive properties of DNWR in all of these datasets have been well-explored in previous analyses - Card \& Hyslop (1997) for the CPS, Kahn (1997) and Altonji \& Devereux (2000) for the PSID, and Nickell \& Quintini (2003) for the NESPD - I do not seek to provide a full descriptive account of DNWR. For reference, though, Tables 1 and 2 present summary statistics for wage changes and the key variables that will be used in the forthcoming analysis. The primary aim of the current section is rather to assess the validity of the predictions of the model presented

\footnotetext{
${ }^{24}$ A selection issue arises when excluding job-changers. In particular, previous research has shown that "displaced" workers often accept significant reductions in earnings on re-employment (see Jacobson, LaLonde \& Sullivan, 1993). Thus, by concentrating on job-stayers, our results might overstate the true extent of DNWR. However, it is also the case that much of the previous literature has focused on job-stayers, so our analysis will be comparable to that of other studies. We leave these empirical issues for future research.

${ }^{25}$ However, much of our analysis requires the use of consistent industry and occupation coding, which we have up to 1999 only.
} 
in section 2. However, it should be noted that the NESPD data for Great Britain have a number of key advantages for the purposes of this paper, especially in comparison with the CPS and PSID samples for the US.

The first, and most obvious, is that the NESPD provides us with comparatively very large sample sizes: one obtains sample sizes of $60-80,000$ wage change observations each year. The second advantage of the NESPD data is its sample period: from 1975-2001. This is particularly useful given that I seek to use variation in the rate of inflation to gauge the impact of DNWR on wage changes, since the UK experienced significant variation in inflation over this period relative to the US. Figure 9 displays the time-series of the leading UK inflation indicator - the Retail Price Index (RPI) - and the CPI-U inflation rate for the US, over the relevant periods. It can be seen that the UK inflation rate varied substantially, with rates over $20 \%$ in the 1970 s down to below $2 \%$ in the 1990s. Inflation in the US, on the other hand, displays much less variation, with rates no higher than $11 \%$.

The final key advantage of the NESPD sample is that measurement error in these data is likely to be less of a problem relative to individually reported data of the CPS and PSID samples. The reason for this is that the NESPD is collected from employers' payroll records, thereby leaving less scope for error due to imperfect memory etc. (see Nickell \& Quintini, 2003, for more on this) ${ }^{26}$. This is important because the existence of measurement error in hourly wages has been shown in previous empirical studies to act as a key impediment to inferring the extent of DNWR. As emphasized throughout this analysis, the existence of a spike at zero in the distribution of nominal wage changes is a key characteristic of DNWR. Classical measurement error in wages and hours data would yield an understatement of the spike by rendering true wage freezes to be observed as (small) wage changes (Akerlof et al., 1996). In contrast, previous studies have also stressed that individuals may round their reported wages yielding an overstatement of the extent of DNWR as small true wage changes are reported as wage freezes (Smith, 2000). Whilst some existing studies have attempted to circumvent this by explicitly modelling measurement error, or using

\footnotetext{
${ }^{26}$ Indeed validation studies of leading panel datasets have used matched data from employer surveys to assess the extent of measurement error in worker reported earnings data. In particular, Bound \& Krueger (1990) and Card \& Hyslop (1997) both seek to assess the importance of measurement error in the CPS via this method.
} 
data from payroll records of individual establishments (Altonji \& Devereux, 1999; Fehr \& Goette, 2003), the relative accuracy of the NESPD allows us to avoid these difficulties and preserve a more representative sample, and is thus an important virtue in this context ${ }^{27}$.

A final note worth making in the context of these datasets is that inflation stayed at persistently low levels in the US and UK from 1992 onwards, with an average inflation rate of $2.56 \%$ for the US 1992-2002 and 2.69\% for the UK 1992-2001. This is important, as a criticism levelled at previous studies of DNWR has been that individuals will get used to receiving nominal wage cuts when inflation has remained low for some time (Gordon, 1996, and Mankiw, 1996). Such a criticism becomes less compelling when the inflation rate has stayed low for the 9-10 years observed in the samples for the CPS and the NESPD.

\subsection{Does DNWR Increase Aggregate Wage Growth?}

In order to test the hypotheses of section 3, one needs a way of modelling empirically the wage change distribution, $f(\Delta \ln W)$. In what follows, I will focus on the analogous real wage change distribution counterpart to this ${ }^{28}$. In order to motivate my preferred method, let us begin by considering some naive approaches. First, one might think of simply looking at the differences between the wage change distributions in high inflation periods and low inflation periods to see if the predictions of section 3 are confirmed at this basic level. To this end, figures 10(a) and 11(a) present estimates of the density of log real wage changes for periods with different inflation rates using the PSID for the US, and the NESPD for Britain (the redesign of the CPS renders this a less useful exercise for the CPS data). Notice that lower inflation leads to a compression of the lower and, more importantly for our purposes, the upper tail of the wage change distribution, precisely in accordance with the predictions of section $4.1^{29}$.

\footnotetext{
${ }^{27}$ It should be noted that hourly earnings in the NESPD are derived from dividing weekly earnings by weekly hours, thereby potentially exacerbating any underlying measurement error. However, Nickell \& Quintini (2003) have compared the accuracy of hourly wage changes in the NESPD with those obtained from a sample whose payslip was checked in the British Household Panel Study and found remarkably similar properties in both datasets.

${ }^{28}$ Note that this does not alter any substantive aspects of the analysis, since this is exactly the same shaped distribution, just shifted to the left by a constant, $\Delta \ln (W / P)=\Delta \ln W-\Delta \ln P \cong \Delta \ln W-\pi$ where $\pi$ is the rate of inflation. However, focusing on real wage changes does allow greater ease of comparison across years with different inflation rates.

${ }^{29}$ It should be noted that the existence of the spike in the lower tail of the real wage change distribution (at approximately minus the rate of inflation) can lead to an overstatement of lower tail compression. However, our
} 
However, one could argue that at least some of the observed differences were due to changes in other variables that affect wage changes. For example, there have been changes in the industrial, age, gender, regional etc. compositions of the workforce in both the US and Britain over these time periods. So, one should control for factors such as these before attributing any differences to DNWR. To address this, I introduce a set of micro-level control variables for each dataset, summarized in Table 2. In particular, I control for changes in micro-level variables by re-weighting the observed wage change distributions according to the method of DiNardo, Fortin \& Lemieux (1996) (henceforth DFL) $)^{30}$. To do this, I first define a "base year", $T$ - for all datasets this will be the final sample year - and re-weight each year's observed wage change distribution to obtain an estimate of what the wage change distribution would have looked like if the distribution of micro-level characteristics were identical to that at date $T$. In particular, if one defines the $\log$ wage change as $\Delta w$, micro-level characteristics as $x$, and the year of the relevant $x$ distribution as $t_{x}$, one can derive that:

$$
f\left(\Delta w_{t} ; t_{x}=T\right)=\int f(\Delta w \mid x) d F\left(x \mid t_{x}=T\right)=\int f(\Delta w \mid x) \cdot \psi \cdot d F\left(x \mid t_{x}=t\right)
$$

for all $t<T$. The key insight of DFL is that this is simply a re-weighted version of the observed date $t$ wage change distribution, with weights $\psi$ given by:

$$
\psi=\frac{d F\left(x \mid t_{x}=T\right)}{d F\left(x \mid t_{x}=t\right)}=\frac{\operatorname{Pr}\left(t_{x}=T \mid x\right)}{\operatorname{Pr}\left(t_{x}=t \mid x\right)} \cdot \frac{\operatorname{Pr}\left(t_{x}=t\right)}{\operatorname{Pr}\left(t_{x}=T\right)}
$$

where the second equality follows from Bayes' Rule. The conditional probabilities in (17) can then be estimated simply via a probit model.

Figures 10(b) and 11(b) displays density estimates of the DFL re-weighted distribution of log real wage changes for different inflation periods, again for the PSID and NESPD. Again, it can be seen clearly that lower rates of inflation are associated with a compression both of tails of the wage change distribution, in line with the predictions of section 3.

emphasis is on the effects on the upper tail, which are not subject to this problem.

${ }^{30} \mathrm{An}$ important benefit of the DFL methodology is that it requires few parametric assumptions on the impact of the $x$ variables. Given the intrinsically non-linear character of the wage policy (13), this is especially helpful. 
However, even having controlled for such factors, it is still not necessarily legitimate to attribute all the residual difference in the wage change distributions to DNWR. Thus we need a way of ensuring that only the variation in wage change distributions that varies systematically with DNWR is attributed. To do this, I estimate regressions of the form:

$$
P_{n_{r t}}=\beta_{0 n}+\beta_{1 n} P_{50_{r t}}+\eta_{n} \boldsymbol{\pi}_{t}+z_{r t}^{\prime} \gamma_{n}+\varepsilon_{n_{r t}}
$$

where $P_{n_{r t}}$ is the $n$th percentile of the real wage change distribution in region $r$ at time $t, \boldsymbol{\pi}_{t}$ is the rate of inflation at time $t$ and thereby measures the prominence of nominal zero in the distribution of log real wage changes, and $z_{r t}$ is a vector of aggregate controls that could potentially affect the distribution of wage changes. $P_{50_{r t}}$ is included on the RHS of (18) in order to control for changes in the central tendency of the distribution of wage changes. That is, it "re-centres" the distributions over time in order to make them comparable. I estimate (18) by Least Squares, where I weight by the size of the region at each date ${ }^{31}$.

The measure of inflation used will be the CPI-U-X1 series for the US, and the April to April log change in the Retail Price Index for Great Britain. The aggregate controls will be as follows. First, I control for any distortion to the wage change distributions caused by peculiarities of the datasets used. So, to control for the effects of survey redesign issues after 1994 in the CPS, I include a dummy variable that takes value one for all years from 1994 onwards when I estimate (18) for the CPS. In addition, to control for the incomes policies implemented in 1977 in the UK, I include a dummy that takes value one for the year 1977 in the NESPD regressions.

In addition, I control for the absolute change in the rate of inflation. This is motivated by the hypothesis that greater inflation volatility will yield greater dispersion in relative wages regardless of the existence of DNWR (see Groshen \& Schweitzer, 1999). I also include both current and lagged regional unemployment rates. This is motivated by the idea that the existence of DNWR might lead to unemployment - indeed, as mentioned before, this is one of the principal reasons

\footnotetext{
${ }^{31}$ Formal quantile regression (Least Absolute Deviation) estimators were also tried with little difference in results. However, such is the computational intensity involved in estimating the correct standard errors for these estimators, we opted for simple OLS instead.
} 
for interest in the topic. Since unemployment will lead to workers "leaving" the wage change distribution, it is important to control for any resulting distributional consequences. I also include lagged regional unemployment in accordance with the wage curve hypothesis of Blanchflower \& Oswald (1994) that the level of wages is empirically associated with the level of unemployment. If this is true, then one would expect the change in unemployment to affect the change in wages, and so I include lagged regional unemployment to control for this possibility.

It should be noted that the empirical method described above is robust to a number of possible concerns. First, the specification is robust to the existence of rigidity in real wages. The reason is that real wage rigidity, in its traditional form, will be invariant to inflation by definition. An exception to this is the argument put forward by Akerlof, Dickens \& Perry (2001) that real wage rigidity is amplified as inflation rises because it becomes optimal for workers to direct their scarce attention to maintaining their real wage. However, if anything, such a possibility would work against the claim of the model in section 2 , as it would predict that the upper tail of wage changes would become more compressed as inflation rises. If this were the case, any evidence I find for the predictions of section 3 could be interpreted as lower bounds on the true effects. A similar reasoning applies to any concerns one might have about the impact of skill-biased technical change (SBTC). Under SBTC, one might expect that workers obtaining high wage increases early in these samples will obtain even higher wage increases later on as technical change increasingly favors those in skilled sectors. However, since inflation is in practice declining over the sample periods of the data, SBTC would, if anything, work against the predictions of section 3.

Clearly, the coefficients of interest in (18) for the purposes of estimating the effects of DNWR are $\eta_{n}$. In particular, the predictions of section 3.2 indicate that $\eta_{n}$ should be negative for low percentiles, and positive for high percentiles. The reasoning is that higher inflation should lead to an increased dispersion of wage changes, and thereby decrease negative percentiles, and increase positive ones.

Recall that we would like to obtain an estimate of the increase in average wage growth due to DNWR, $\lambda \equiv E(\Delta w \mid D N W R)-E(\Delta w \mid n o D N W R)$. Such an estimate can be obtained using the estimates obtained from regressions of the form (18). In order to use this information to get an 
estimate of $\lambda$, I obtain an estimate of the predicted average wage change when inflation is very low (e.g. 1.3\% in 1993 for Britain) and subtract the analogous average wage change when inflation is very high (e.g. $21.8 \%$ in 1980 for Britain $)^{32}$ :

$$
\hat{\lambda}=\hat{E}(\Delta w \mid \boldsymbol{\pi}=1.3 \%, x, z)-\hat{E}(\Delta w \mid \boldsymbol{\pi}=21.8 \%, x, z)
$$

To obtain these estimates using (18), one can use the fact that the quantiles of a random variable are uniformly distributed. In particular, if one estimates $k$ equi-spaced percentiles of $f(\Delta w)$ then a best guess of the predicted average wage change is:

$$
E(\Delta w \mid \boldsymbol{\pi}, x, z) \approx \frac{1}{2(k-1)} \sum_{i=1}^{k-1}\left(\hat{P}_{i}+\hat{P}_{i+1}\right)
$$

where $i$ is an ascending index of the percentiles, with $i=1$ indicating the lowest percentile, $i=2$ the second lowest etc., and the $\hat{P}_{\mathrm{S}}$ are the predicted values of these percentiles obtained from estimating equation (18).

Since these predicted percentiles allow us to sketch out a discretization of the whole distribution of wage changes, I can also decompose the increase in average wage growth due to DNWR into two components. The first is the increase in average wage growth due to compressed nominal wage cuts, which I refer to as "lower tail losses"; the second is the decrease in average wage growth due to compressed wage increases, "upper tail gains". In practice, I will perform this procedure on 99 estimated wage change percentiles, $\hat{P}_{1}, \hat{P}_{2}, \ldots, \hat{P}_{99}$, for the specification detailed above.

\section{The Effects of Measurement Error}

As mentioned previously, the impact of measurement error on the ability to infer the effects of DNWR has received substantial attention in the literature. Whilst I have attempted to mitigate this as a problem by using the relatively clean data in the NESPD for Britain, the question arises as to the effects of measurement error on the methodology detailed above. Proposition 7 answers this question:

\footnotetext{
${ }^{32}$ Note that this involves out-of-sample predictions for the US data.
} 
Proposition 7 If measurement error is independent of the rate of inflation, then (i) estimates of $\eta_{n}$ in (18) report attenuated estimates of the corresponding true effects; (ii) this attenuation vanishes for sufficiently high and low percentiles; and (iii) estimates of $\lambda$ based on (20) will nonetheless remain consistent.

The intuition for this is quite straightforward ${ }^{33}$. The existence of measurement error will render some true negative wage changes to be observed as positive wage changes (and vice versa). Thus, measurement error will lead to a partial conflation of the effects of inflation on the upper tail with those in the lower tail. However, as one proceeds further into the tails of the wage change distribution, the likelihood of measurement error having displaced observations in this way becomes smaller. Thus, such attenuation will disappear for sufficiently high or low percentiles.

Whilst this result does mean that a certain caution should be afforded to the interpretation of the magnitude of the estimated coefficients from (18), the main question under discussion is a qualitative one: does lower inflation compress both the upper and lower tails of the wage change distribution? To this end, the above attenuation result will actually reduce the ability to observe any such compression, should it exist. Thus, any evidence of compression that might be found would be found despite the existence of measurement error, rather than because of it.

The final part of Proposition 7 results from the fact that, by definition, the mean of any random variable can always be expressed as an unweighted average of its percentiles. Since measurement error is assumed independent of the rate of inflation (see Gottschalk, 2004, for evidence that this is empirically the case), it follows that the observed mean wage change at any given rate of inflation will be unaffected by the existence of measurement error. Thus, estimates of $\lambda$ based on (20) should also be unaffected by measurement error.

\section{Empirical Results}

I estimate (18) in three specifications. First, I simply include controls for the median wage change, $P_{50}$, and for any dataset peculiarities such as the CPS survey redesign from 1994 onwards and

\footnotetext{
${ }^{33}$ It should be noted, however, that this attenuation result is quite distinct from the traditional attenuation bias resulting from errors in variables when implementing OLS.
} 
incomes policies of 1977 in the NESPD. I then include controls for the absolute change in the rate of inflation, and for regional current and lagged unemployment rates. Finally, I implement a specification with full controls that estimates (18) using percentiles of the DFL re-weighted wage change distributions so I can control for an array of micro-level characteristics as well.

The results from estimating the three specifications of (18) for each dataset are reported in Tables 3-5. First, consider the results obtained for the CPS in Table 3. In all three specifications it can be seen that the estimated impact of inflation is negative for the 20th-30th percentiles, with strongest effects around the 30th percentile; and positive for the 40th-90th percentiles, with strong effects in the 60th-90th percentiles. Thus, these results are in line with the hypothesis that higher inflation reduces the compression of both tails of the wage change distribution. Moreover, it can be seen that the estimated effects of inflation at different points in the distribution are generally significant and fairly stable across all specifications. In addition, Table 3 presents estimates of the lower tail losses and upper tail gains due to DNWR. It can be seen that in all specifications there are substantial savings due to compressed wage increases, some of which even outweigh the costs from compressed wage cuts.

Table 4 reports the analogous estimates for the PSID data. It can be seen that in all specifications the effect of inflation is negative for the 10th-20th percentiles, and positive for the 40th-90th percentiles. However, here the estimated effects are strongest in the 10th, and particularly the 20th, percentiles in the lower tail in contrast to the CPS results. The differences in the lower tail effects between the CPS and PSID results are likely to reflect the differences in the position of nominal zero in the respective wage change distributions, due to higher rates of inflation in the PSID sample period. In the CPS, nominal zero appears mostly between the 20th and 35th percentiles, whereas it appears at around the 10th-35th percentile in the PSID sample. Thus, the point at which DNWR binds differs across these two datasets.

The PSID results are broadly as significant as those for the CPS, with both lower and upper tail effects remaining significant, and fairly stable across specifications. In addition, the coefficient estimates in the upper tail are comparable to those obtained in the CPS results, and one again can observe that there are large savings from the compression of the upper tail. In particular, I find 
an estimated increase in average wage growth due to lower tail losses of around $1-1.2 \%$ which is offset by a reduction in average wage growth due to upper tail compression of $0.9-1.1 \%$. It should however be noted that for the PSID, and to some extent the CPS data, these estimates are constructed from a number of regressions for which no significant inflation effect was detected. This is likely due to the relative lack of observations and inflation variation in the CPS and PSID compared to the NESPD. Thus, I do not want to place too much stock in the actual quantitative estimates obtained from this dataset. Rather, I consider the estimates of upper tail gains and lower tail losses for the PSID to be instructive of the fact that there is some significant compression of the upper tail of wage changes, and that this compression is of similar significance and magnitude to the compression of the lower tail due to DNWR.

The results for the NESPD data are reported in Table 5. Again I observe that inflation has a negative impact on lower percentiles (10th-40th) and a positive impact on higher percentiles (60th-90th). Moreover, I obtain highly significant estimates for almost all percentiles and in all specifications. As mentioned above, this greater significance in comparison to the results for the PSID and the CPS is likely to be due to the larger sample sizes, more precise wage information, and large variation in inflation in the NESPD. In addition, one can again observe substantial upper tail gains due to compression of wage increases relative to lower tail losses, which are more consistent across specifications than those obtained for the CPS and the PSID. In particular, the results suggest that $75-95 \%$ of the lower tail losses due to DNWR is saved by restricting wage increases in the upper tail in the NESPD data, and that the increase in average real wage growth due to DNWR is of the order $0.04-0.3 \%$ - much lower than results obtained previously.

Together, these results provide strong evidence for the prediction that the upper tail of the wage change distribution will be less dispersed as a result of DNWR - in all specifications and for all datasets one can see that wage increases become more restricted as inflation falls. As a result, by allowing both the upper and lower tails of the wage change distribution to be affected by DNWR, the estimated increase in average wage growth due to DNWR becomes much reduced and closer to zero - precisely in line with the predictions of section 3 and Proposition 5. 


\subsection{Does Higher Turnover Reduce the Compression of Wage Increases?}

In addition to the above, recall that section 3.3 established the claim that higher turnover sectors should act more myopically, will thus feel more at liberty to raise nominal wages, but that such an effect should fade as inflation rises ${ }^{34}$. I test this hypothesis in a manner similar to that employed in section 4.2. First, I define a measure of "turnover" as the fraction of workers that changes jobs each year in a given occupation, region group. In a steady state this should closely match the fraction of workers who separate, and thus correspond to the parameter $\delta$ in section 3.3.

To gain an initial impression for whether such effects exist, Figure 12(a) plots density estimates of the nominal wage change distribution for job stayers in high and low turnover (respectively above and below median turnover) occupations using the NESPD data ${ }^{35}$. It can be seen from this simple comparison that low turnover occupations seem to be compressing wage increases much more than high turnover occupations.

However, recall that section 3.3 noted that these effects should be manifested through changes in the active compression of wage increases, and thus relate to the properties of the conditional distribution, $f\left(\Delta \ln W \mid W_{-1}\right)$. To address this issue, Figure 12(b) replicates the exercise but controls for the covariates listed in Table 2, as well as the lagged wage ${ }^{36}$, using the DFL technique. This allows us to control for any micro-level factors that may be driving the results, as well to focus on variation in the distribution of wage changes conditional on the lagged wage. Again, however, one can see low turnover occupations compressing wage increases more than high turnover occupations, consistent with the predictions of section 3.3.

To complete the picture, panels (c) and (d) of Figure 12 attempt to assess whether the effect of turnover on the distribution of wage changes varies with the rate of inflation. It can be seen that

\footnotetext{
${ }^{34}$ Note that we are making a claim about the effects of turnover on the distribution of wage growth rather than mean wage growth. Clearly, there are additional concerns that would relate turnover to mean wage growth such as effects on tenure, match quality etc. These are not however related to compression of the distribution of wage growth emphasized here.

${ }^{35}$ Since tenure is not reported in the CPS, and is subject to changes in definition in the PSID, we concentrate on the NESPD data for this section.

${ }^{36}$ In particular, we use the lagged wage adjusted for inflation and productivity growth, $\tilde{W}_{t-1} \equiv W_{t-1} \cdot \frac{P_{T-1}}{P_{t-1}} \cdot \frac{a_{T-1}}{a_{t-1}}$, where $a_{s}$ is measured as GDP per hour in year $s$. This is legitimate provided that DNWR has no impact on either price or productivity growth. Given Proposition 5 and the results of section 4.2 this does not seem unreasonable.
} 
the compression of wage increases due to lower turnover appears to be stronger in periods of low inflation, as predicted by the model of section 2. Together, then, there appears to be suggestive evidence that the predictions of section 3.3 are supported in the data.

To identify these turnover effects more formally, however, I run Least Squares regressions of the form:

$$
P_{n_{\text {ort }}}=\alpha_{0 n}+\alpha_{1 n} P_{50_{\text {ort }}}+\theta_{n} \boldsymbol{\tau}_{\text {ort }}+\eta_{n} \boldsymbol{\pi}_{t}+\iota_{n}\left(\boldsymbol{\pi}_{t} \times \boldsymbol{\tau}_{\text {ort }}\right)+z_{\text {rt }}^{\prime} \psi_{n}+\varepsilon_{n_{\text {ort }}}
$$

where $P_{n_{\text {ort }}}$ now refers to the $n$th percentile of nominal wage changes for job stayers, re-weighted for micro covariates and the lagged wage, in occupation $o$, region $r$, at time $t$. The variable of interest is $\boldsymbol{\tau}_{\text {ort }}$ which denotes the fraction of job changers in an occupation, region, year cell. Under the predictions of section 3.3, one would expect that the coefficients on turnover, $\theta_{n}$, to be positive, the coefficients on inflation, $\eta_{n}$, to be positive, and the coefficients on the interaction term, $\iota_{n}$, to be negative, for all positive percentiles of nominal wage changes.

Table 6 summarizes these estimates for the 60-90th percentiles. In the first specification (column 1), I include only basic controls for the median wage change and a dummy for 1977 to control for the incomes policies of that time, and exclude the rate of inflation and its interaction with turnover. It can be clearly seen that turnover has a positive and highly significant impact on the 60-90th percentiles of nominal wage changes. The two additional columns address potential concerns one might have about the simple specification of column (1).

In particular, one concern might be that one would expect sectors with greater DNWR to have greater rates of turnover due to workers being made unemployed more often. In addition, one would also expect sectors with greater DNWR to exhibit a greater compression of wage increases, and thus create downward pressure on percentiles of wage increases. In this sense there may be an omitted variable - the extent of DNWR - that will lead to bias in the estimates of column (1). In particular, it would imply a downward bias to the estimates. Column (2) seeks to assess this possibility by including the current and lagged regional unemployment rates as controls. It can be seen, however, that this actually reduces the estimated effects of turnover, which nevertheless remain positive and highly significant. Thus, there does not appear to be strong evidence for an 
omitted variables problem of this type.

However, one may still be concerned that the measure of turnover is more generally cyclical, and thus potentially correlated with the rate of inflation. Thus one may be worried that the above results are attributing to turnover the effects due to declining inflation. One may also be concerned that the effects of inflation found in section 4.2 are not robust to the addition of turnover as a control. Finally, one would like to assess whether the effect of turnover on the distribution of wage changes diminishes as inflation rises. To address these concerns, specification (3) includes the rate of inflation and the interaction between inflation and turnover as regressors. It can be seen that introducing these controls does not significantly alter the estimated effects of turnover, and that the coefficients remain positive and highly significant. Moreover, I find that the effect of inflation is robust to the addition of turnover as a control, and remains positive and highly significant for all except the 90th percentile of wage changes.

The coefficients on the interaction between turnover and inflation are less successful, however. In particular, the estimates are positive, but close to zero and highly insignificant for the 60th and 70th percentiles. The estimates for the 80th and 90th percentiles are negative and much larger

in magnitude - in accordance with the "behavioral" model's predictions - though the effect is significant only at the 80 th percentile. However, these latter estimates imply that a $20 \%$ inflation rate will reduce the effect of turnover on the distribution of wage changes by $50-60 \%$.

I thus find robust evidence that increased turnover leads to an increased dispersion of wage increases, that the effects of turnover and inflation are mutually robust, and that there is suggestive evidence that the effects of turnover are reduced as inflation rises, broadly in line with the predictions of section 3.3 .

\section{Conclusions}

This paper has shown that a model of allocative downward nominal wage rigidity driven by worker resistance to nominal wage cuts is nevertheless consistent with weak macroeconomic effects. It has shown as a theoretical issue that DNWR should have no effect on aggregate wage growth in 
the long run, and that this is achieved because firms compress wage increases as well as wage cuts when DNWR binds. Moreover, it has shown that, by neglecting potential compression of wage increases, the previous literature may well have overstated the increase in aggregate wage growth due to DNWR, and thereby substantially overstated the costs of DNWR to firms.

Taking these predictions to a broad range of micro-data on wages from the US and Great Britain I find that firms do indeed compress wage increases as well as wage cuts at times when DNWR binds. Furthermore I find that accounting for the compression of wage increases reduces the estimated increase in aggregate wage growth due to DNWR to be much closer to zero, consistent with the predictions of the model. Together, the results suggest that the existence of DNWR may not provide a strong argument against the targeting of low inflation rates, as practiced by many monetary authorities. Importantly, though, this result is nevertheless consistent with the wide array of evidence that suggests workers are averse to nominal wage cuts.

Stepping back from this, one might ask whether the key mechanism put forward in this paper - that firms may compress wage increases in the face of DNWR - really rings true in the real world. There is, in fact, subjective evidence that wage setters and workers do think along these lines. Following his original study (Bewley, 1999), Bewley has since reported that:

"[Business leaders] take account of the fact that, if they raise the level of pay today, it will remain high in the future. I hear a lot about this last point now. [...] Some say that they are not now increasing pay [...] because they know they will not be able to reverse the increases during the next downturn." Bewley (2000), p.46.

In addition, there is evidence of explicitly bargained mediation of wage growth as an alternative to wage cuts:

"General Motors Corp's historic health care deal with the United Auto Workers will require active workers to forgo $\$ 1$-an-hour in future wage hikes [...] Allen Wojczynski, a 36-year GM employee, said the company's proposal seems acceptable [...] He had been expecting the automaker to ask its workers for pay cuts to trim health care costs. 'I 
could live with it, giving up $\$ 1$ an hour of my future pay raises,' said Wojczynski [...]"

Detroit News, October 21st 2005. ${ }^{37}$

Thus, compression of wage raises is a practical approach to limiting labor costs in the face of poor economic conditions, and can thereby limit disemployment effects of worker resistance to wage cuts.

\section{References}

Abel, Andrew B., and Janice C. Eberly, "Optimal Investment with Costly Reversibility", Review of Economic Studies, Vol. 63, No. 4. (Oct., 1996), pp. 581-593.

Akerlof, George A., William T. Dickens, and George L. Perry, "The Macroeconomics of Low Inflation", Brookings Papers on Economic Activity, Vol. 1996, No. 1. (1996), pp. 1-76.

Akerlof, George A., William T. Dickens, and George L. Perry, "Near Rational Wage and Price Setting and the Long-Run Phillips Curve", Brookings Papers on Economic Activity, Vol. 2000, No. 1. (2000), pp. 1-44.

Akerlof, George A., and Janet L. Yellen, Efficiency Wage Models of the Labor Market, Cambridge University Press, 1986.

Altonji, Joseph \& Paul Devereux, "The Extent and Consequences of Downward Nominal Wage Rigidity", Research in Labor Economics, Vol 19, Elsevier Science Inc. (2000): 383-431.

Barro, Robert J., "Long-Term Contracting, Sticky Prices, and Monetary Policy," Journal of Monetary Economics, 3, (1977), 305-316.

Bentolila, Samuel, and Giuseppe Bertola, "Firing Costs and labor Demand: How Bad is Eurosclerosis?", Review of Economic Studies, Vol. 57, No. 3. (Jul., 1990), pp. 381-402.

Bewley, Truman F., Why wages don't fall during a recession, Cambridge and London: Harvard University Press, 1999.

Bewley, Truman F., Comment on Akerlof, George A., William T. Dickens, and George L. Perry, "Near Rational Wage and Price Setting and the Long-Run Phillips Curve", Brookings Papers on Economic Activity, Vol. 2000, No. 1. (2000), pp. 1-44.

Blanchflower, David G., Andrew J. Oswald, The Wage Curve, Cambridge and London: MIT Press, 1994.

Bloom, Nicholas, "The Real Options Effect of Uncertainty on Investment and labor Demand", IFS Working Paper, November 2000.

\footnotetext{
${ }^{37}$ See http://www.detnews.com/2005/autosinsider/0510/21/A01-356532.htm. This is not to claim that the latter agreement is the key solution to this particular labor conflict; just that it is indicative that the results of this paper bear some resemblance to wage setting in the real world.
} 
Cairncross, Alec, The British Economy since 1945, 2nd edition, Blackwell, 1995.

Card, David \& Dean Hyslop "Does Inflation 'Grease the Wheels of the Labor Market'?" in Christina D. Romer and David H. Romer, editors, Reducing Inflation: Motivation and Strategy. University of Chicago Press, 1997.

DiNardo, John, Nicole M. Fortin, and Thomas Lemieux, "Labor Market Institutions and the Distribution of Wages, 1973-1992: A Semiparametric Approach", Econometrica, Vol. 64, No. 5. (Sep., 1996), pp. 1001-1044.

Dickens, William T., Lorenz Goette, Erica L. Groshen, Steinar Holden, Julian Messina, Mark E. Schweitzer, Jarkko Turunen, and Melanie Ward, "The Interaction of Labor Markets and Inflation: Analysis of Micro Data from the International Wage Flexibility Project," mimeo Brookings Institution, 2006.

Fehr, E. \& L. Götte, "Robustness and Real Consequences of Nominal Wage Rigidity," Institute for Empirical Research in Economics, University of Zürich, Working Paper No. 44.

Genesove, David \& Christopher Mayer, "Loss Aversion and Seller Behavior: Evidence from the Housing Market", Quarterly Journal of Economics. November 2001; 116(4): 1233-60.

Gordon, R., Comment on: Akerlof, George A., William T. Dickens, and George L. Perry, "The Macroeconomics of Low Inflation", Brookings Papers on Economic Activity, Vol. 1996, No. 1. (1996), pp. 1-76.

Gottschalk, Peter, "Downward Nominal Wage Flexibility: Real or Measurement Error?", IZA Discussion Paper no. 1327, October 2004.

Groshen, Erica L., and Mark E. Schweitzer, "Identifying Inflation's Grease and Sand Effects in the Labor Market", Feldstein, Martin, ed. The costs and benefits of price stability. NBER Conference Report series. Chicago and London: University of Chicago Press, 1999; 273-308.

Hirsch, Barry T., and Edward J. Schumacher, "Match Bias in Wage Gap Estimates Due to Earnings Imputation", Journal of Labor Economics, 2004, vol. 22, no. 3.

Howitt, Peter, "Looking Inside the Labor Market: A Review Article", Journal of Economic Literature 40 (March 2002): 125-38.

Jacobson, Louis S., Robert J. LaLonde, and Daniel G. Sullivan, "Earnings Losses of Displaced Workers" American Economic Review, Vol. 83, No. 4. (Sep., 1993), pp. 685-709.

Kahn, Shulamit, "Evidence of Nominal Wage Stickiness from Microdata", American Economic Review, Vol. 87, No. 5. (Dec., 1997), pp. 993-1008.

Kahneman, Daniel, Jack L. Knetsch, and Richard Thaler, "Fairness as a Constraint on Profit Seeking: Entitlements in the Market", American Economic Review, Vol. 76, No. 4. (Sep., 1986), pp. 728-741.

Kahneman, Daniel, and Amos Tversky, "Prospect Theory: An Analysis of Decision under Risk", Econometrica, Vol. 47, No. 2. (Mar., 1979), pp. 263-292. 
Keynes, John Maynard, The General Theory of Employment, Interest, and Money, 1936.

Kramarz, F., "Rigid Wages: What Have we Learnt from Microeconometric Studies", in Advances in Macroeconomic Theory, J. Drèze ed., 194-216, Oxford University Press, Oxford, UK.

Lebow, David E., Raven E. Saks, Beth-Anne Wilson, "Downward Nominal Wage Rigidity: Evidence from the Employment Cost Index", Board of Governors of the Federal Reserve System, Finance and Economics Discussion Series: 99/31 July 1999.

Madrian, Brigitte, and Lars J. Lefgren, "A Note on Longitudinally Matching Current Population Survey (CPS) Respondents" NBER Technical Working Paper 247, November 1999.

Mankiw, N. G., Comment on: Akerlof, George A., William T. Dickens, and George L. Perry, "The Macroeconomics of Low Inflation", Brookings Papers on Economic Activity, Vol. 1996, No. 1. (1996), pp. 1-76.

Nickell, S., and Glenda Quintini, "Nominal wage rigidity and the rate of inflation", Economic Journal, October 2003, vol. 113, no. 490, pp. 762-781(20).

Shafir, Eldar, Peter Diamond, and Amos Tversky, "Money Illusion", Quarterly Journal of Economics. May 1997; 112(2): 341-74.

Smith, Jennifer, "Nominal wage rigidity in the United Kingdom", Economic Journal 110 (March 2000), 176-195.

Smith, Jennifer, "How Costly is Downward Nominal Wage Rigidity in the UK?", mimeo, December 2004.

Solow, Robert M., "Another Possible Source of Wage Stickiness", Journal of Macroeconomics, Vol. 1, pp.79-82, Winter 1979.

Stokey, Nancy L., and Robert E. Lucas Jr., Recursive methods in economic dynamics, with Edward C. Prescott Cambridge, Mass. and London: Harvard University Press, 1989.

Tobin, James, "Inflation and Unemployment," American Economic Review, Vol. 62, No. 1/2. (1972), pp. 1-18.

\section{Appendix}

\section{A Lemmas and Proofs}

Lemma 1 The value function defined in (5) has the following properties:

$$
\begin{aligned}
v_{W}^{-}\left(W, A^{\prime}\right) & =-c \frac{A^{\prime}}{W} \\
v_{W}^{0}\left(W, A^{\prime}\right) & =\frac{A^{\prime}}{W}-1+\frac{\beta}{1+\pi} D\left(W, A^{\prime}\right) \\
v_{W}^{+}\left(W, A^{\prime}\right) & =0
\end{aligned}
$$


Proof. First, note that standard application of the Envelope Theorem implies:

$$
\begin{aligned}
v_{W}^{-}\left(W, A^{\prime}\right) & =c \frac{A^{\prime}}{W} \\
v_{W}^{+}\left(W, A^{\prime}\right) & =0
\end{aligned}
$$

It is only slightly less obvious what happens when $\Delta W^{\prime}=0$, i.e. when the wage is not adjusted. In this case, $W^{\prime}=W$ and this implies that:

$$
v^{0}\left(W, A^{\prime}\right)=A^{\prime} \ln \left(\frac{W}{B^{\prime}}\right)-W+\frac{\beta}{1+\pi} \int v\left(W, A^{\prime \prime}\right) d F\left(A^{\prime \prime} \mid A^{\prime}\right)
$$

It therefore follows that:

$$
v_{W}^{0}\left(W, A^{\prime}\right)=\frac{A^{\prime}}{W}-1+\frac{\beta}{1+\pi} \int v_{W}\left(W, A^{\prime \prime}\right) d F\left(A^{\prime \prime} \mid A^{\prime}\right)
$$

Since, by definition $D\left(W, A^{\prime}\right) \equiv \int v_{W}\left(W, A^{\prime \prime}\right) d F\left(A^{\prime \prime} \mid A^{\prime}\right)$, the statement holds as required.

Proof of Proposition 2. First, note that one can re-write the continuation value conditional on each of the three possible continuation regimes:

$$
v\left(W, A^{\prime}\right)=\left\{\begin{array}{lll}
v^{-}\left(W, A^{\prime}\right) & \text { if } & A^{\prime}<A_{l}^{\prime} \\
v^{0}\left(W, A^{\prime}\right) & \text { if } & A^{\prime} \in\left[A_{l}^{\prime}, A_{u}^{\prime}\right] \\
v^{+}\left(W, A^{\prime}\right) & \text { if } & A^{\prime}>A_{u}^{\prime}
\end{array}\right.
$$

where superscripts $-/ 0 /+$ refer to whether the nominal wage is cut, frozen, or raised tomorrow. Note also that, due to the recursive nature of the problem:

$$
\begin{aligned}
A_{l} \equiv l\left(W_{-1}\right) ; & & A_{u} \equiv u\left(W_{-1}\right) \\
\Longrightarrow A_{l}^{\prime} \equiv l(W) ; & & A_{u}^{\prime} \equiv u(W)
\end{aligned}
$$

Thus we can write ${ }^{38}$ :

$$
\int v\left(W, A^{\prime}\right) d F\left(A^{\prime} \mid A\right)=\int_{0}^{l(W)} v^{-}\left(W, A^{\prime}\right) d F+\int_{l(W)}^{u(W)} v^{0}\left(W, A^{\prime}\right) d F+\int_{u(W)}^{\infty} v^{+}\left(W, A^{\prime}\right) d F
$$

Taking derivatives with respect to $W$ and recalling the definition of $D(\cdot)$, and noting that, since $v\left(W, A^{\prime}\right)$ is continuous, it must be that $v^{-}(W, l(W))=v^{0}(W, l(W))$ and $v^{0}(W, u(W))=v^{+}(W, u(W))$ yields:

$$
D(W, A)=\int_{0}^{l(W)} v_{W}^{-}\left(W, A^{\prime}\right) d F+\int_{l(W)}^{u(W)} v_{W}^{0}\left(W, A^{\prime}\right) d F+\int_{u(W)}^{\infty} v_{W}^{+}\left(W, A^{\prime}\right) d F
$$

Finally, using the Envelope conditions in Lemma 1, and substituting into (29) we obtain (9) in the main text:

$$
D(W, A)=\int_{l(W)}^{u(W)}\left[\frac{A^{\prime}}{W}-1\right] d F-\int_{0}^{l(W)} c \frac{A^{\prime}}{W} d F+\frac{\beta}{1+\pi} \int_{l(W)}^{u(W)} D\left(W, A^{\prime}\right) d F \equiv(\mathbf{C} D)(W, A)
$$

\footnotetext{
${ }^{38}$ Henceforth, " $d F "$ without further elaboration is to be taken as " $d F\left(A^{\prime} \mid A\right)$ ".
} 
To verify that $\mathbf{C}$ is a contraction mapping over the "relevant range" (to be defined shortly), we confirm that Blackwell's sufficient conditions for a contraction hold here (see Stokey \& Lucas, 1989, p.54). First, note that any values for $(W, A)$ that render $\mathbf{C}$ unbounded cannot obtain under optimality, since they will necessarily violate the conditional first-order condition, (6). Thus, we can restrict our attention to a subset of values for $(W, A)$ around the optimum for which $\mathbf{C}$ is bounded. This is what we define as the "relevant range". That $\mathbf{C}$ then maps the space of bounded functions into itself over this range holds by definition. Given this, monotonicity and discounting are straightforward to verify. To verify monotonicity, fix $(W, A)=(\bar{W}, \bar{A})$, and take $\hat{D} \geq D$. Then note that:

$$
\begin{aligned}
\int_{l(\bar{W})}^{u(\bar{W})} \hat{D}\left(\bar{W}, A^{\prime}\right) d F\left(A^{\prime} \mid \bar{A}\right)- & \int_{l(\bar{W})}^{u(\bar{W})} D\left(\bar{W}, A^{\prime}\right) d F\left(A^{\prime} \mid \bar{A}\right) \\
= & \int_{l(\bar{W})}^{u(\bar{W})}\left[\hat{D}\left(\bar{W}, A^{\prime}\right)-D\left(\bar{W}, A^{\prime}\right)\right] d F\left(A^{\prime} \mid \bar{A}\right) \geq 0
\end{aligned}
$$

Since $(\bar{W}, \bar{A})$ were arbitrary, it thus follows that $\mathbf{C}$ is monotonic in $D$. To verify discounting, note that:

$$
\begin{aligned}
{[\mathbf{C}(D+a)](W, A) } & =(\mathbf{C} D)(W, A)+\frac{\beta}{1+\pi} a[F(u(W) \mid A)-F(l(W) \mid A)] \\
& \leq(\mathbf{C} D)(W, A)+\frac{\beta}{1+\pi} a
\end{aligned}
$$

Since we know that $\frac{\beta}{1+\pi}<1$ it follows that $\mathbf{C}$ is a contraction over the relevant range. It therefore follows from the Contraction Mapping Theorem that $\mathbf{C}$ has a unique fixed point over the relevant range.

Proof of Proposition 5. Denote the counterfactual nominal wage at time $t$ as $W_{t}^{*}=A_{t}$. We seek the properties of the difference in average wage growth between the "actual" (with DNWR) and counterfactual cases, which we define as $\lambda$ :

$$
\begin{aligned}
\lambda_{T} & \equiv \frac{1}{T} \sum_{s=t+1}^{t+T} \ln \left(\frac{W_{s}}{W_{s-1}}\right)-\frac{1}{T} \sum_{s=t+1}^{t+T} \ln \left(\frac{W_{s}^{*}}{W_{s-1}^{*}}\right) \\
& =\frac{1}{T}\left\{\ln \left(\frac{W_{t+T}}{W_{t+T}^{*}}\right)-\ln \left(\frac{W_{t}}{W_{t}^{*}}\right)\right\}
\end{aligned}
$$

Then note that, from the optimal wage policy of the firm, (13), it follows that the log-difference between the actual and counterfactual wages must be bounded, $\ln \left(W_{t} / W_{t}^{*}\right) \in[-\ln u,-\ln l]$. Thus:

$$
\begin{aligned}
\sup \lambda_{T} & =\frac{1}{T}[\ln u-\ln l]=\frac{1}{T} \ln G \\
\inf \lambda_{T} & =\frac{1}{T}[\ln l-\ln u]=-\frac{1}{T} \ln G
\end{aligned}
$$

Therefore, for finite $G, \lim _{T \rightarrow \infty} \sup \lambda_{T}=0=\lim _{T \rightarrow \infty} \inf \lambda_{T}$.

Proof of Proposition 6. (i) Define the increase in wage growth due to DNWR in the 
median-symmetric (MS) case as:

$$
g \equiv \int_{-\infty}^{0} x f(x) d x-\int_{-\infty}^{0} x \hat{f}(x) d x
$$

where $f$, and $\hat{f}$ are respectively the observed, and MS counterfactual log wage change densities. Further define the true average cost of DNWR as $\mathbb{C} \equiv E\left(v^{*}-v\right)$ where $v^{*}$ denotes the true frictionless value of a firm. Taking a first order Taylor series approximation around $c=0$ yields:

$$
\left.\mathbb{C} \stackrel{c=0}{\approx} \frac{d \mathbb{C}}{d c}\right|_{c=0} \cdot c
$$

Note first that $d \mathbb{C} /\left.d c\right|_{c=0}=-\left.\left[\frac{\partial v}{\partial c}+\frac{\partial v}{\partial W} \cdot \frac{\partial W}{\partial c}\right]\right|_{c=0}=-E \sum_{t=0}^{\infty} \beta^{t} a_{t} \Delta \ln A_{t} \mathbf{1}_{t}^{-}=-E\left(\Delta \ln A \mathbf{1}^{-}\right) \frac{E(a)}{1-\beta}$, since $\partial v /\left.\partial W\right|_{c=0}=0$, and where the second equality follows from the stationarity of, and the independence of increments to, the shock process. It follows from this that the costs of DNWR are entirely driven by reductions in effort following wage cuts. Next, note that by using the definition of $G$ in (55) one can show that $\ln G \stackrel{c=0}{\approx} c$.

The final step for part $(i)$ is to show that $\ln G \approx g / \operatorname{Pr}(\Delta \ln A<0)$. Recall that in the wage cut regime, $\Delta \ln W=\ln \left(A / W_{-1}\right)-\ln l=\ln \left(A / A_{-s}\right)-\ln l+\ln \kappa_{-s}$, since $W_{-1}=A_{-s} / \kappa_{-s}$, where $s$ is the number of periods since the last wage change, and $\kappa_{-s} \in\{l, u\}$ depending on whether the last wage change was negative or positive. Then note that if one were to assume that observed wage increases were unaffected by DNWR, one implicitly assumes that the counterfactual wage change is given by $\Delta \ln \hat{A}=\ln \left(A / W_{-1}\right)-\ln u=\ln \left(A / A_{-s}\right)-\ln u+\ln \kappa_{-s}$. If follows that, for a given $s$, $\hat{f}(x)=f(x+\ln G)$. Thus, for a given $s$,

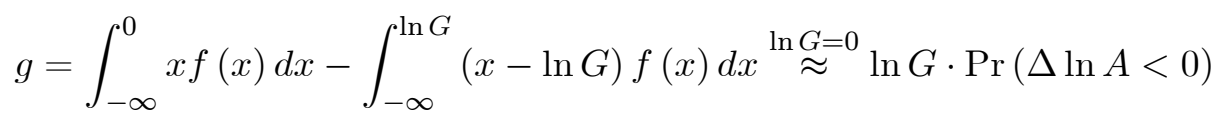

which is independent of $s$. It follows that $g \approx \ln G \cdot \operatorname{Pr}(\Delta \ln A<0)$ as required. Piecing these components together we obtain:

$$
\mathbb{C}^{c=0} \approx-g \cdot E(\Delta \ln A \mid \Delta \ln A<0) \cdot \frac{E(a)}{1-\beta}
$$

(ii) Previous studies asserted that DNWR is costly because it raises the cost of labor, and thereby sought to estimate these increased costs. In this way, they identify the costs of DNWR to be equal to:

$$
\mathbb{W} \equiv E \sum_{t=0}^{\infty} \beta^{t}\left(\omega_{t}-\omega_{t}^{*}\right)=E \sum_{t=0}^{\infty} \beta^{t} \prod_{n=1}^{t}\left(1+g_{n}\right) \omega_{0}-\frac{E(a)}{1-\beta}
$$

where $g_{n}$ is the (random) growth rate of real wages in period $n$. From the above definition of $g$, $E\left(g_{n}\right) \equiv g$. Together with the stationarity of the increments to the shock process, this implies that $E\left(g_{n} \mid g_{n-1}, g_{n-2}, \ldots\right)=g$; i.e. that the $g$ s are independent of each other. Thus:

$$
\mathbb{W}=\frac{E\left(\omega_{0}\right)}{1-\beta-\beta g}-\frac{E(a)}{1-\beta}
$$

According to Proposition 5, of course, the "true" value of $g$ is zero. Thus the overstatement of the 
wage costs of DNWR under the MS methodology is given by:

$$
\frac{\beta g}{1-\beta-\beta g} \frac{E\left(\omega_{0}\right)}{1-\beta} \stackrel{g=0}{\approx} g \cdot \frac{\beta}{1-\beta} \cdot \frac{E(a)}{1-\beta}
$$

as required.

Proof of Proposition 7. (i) By definition, $F\left(P_{n}\right) \equiv n / 100$. Totally differentiating yields:

$$
\frac{\partial P_{n}}{\partial \pi}=\left.\frac{-\partial F / \partial \pi}{f(\Delta w)}\right|_{\Delta w=P_{n}}
$$

Now, defining measurement error as $\epsilon$ with $\operatorname{cdf} G(\epsilon)$, it follows that the cdf of observed wage changes, $\Delta w$, is given by $F(\Delta w)=\int F^{*}\left(\Delta w^{*} \mid \epsilon\right) d G(\epsilon)$ where $F^{*}$ is the cdf of true wage changes, $\Delta w^{*} \equiv \Delta w-\epsilon$. It follows that:

$$
\frac{\partial F}{\partial \pi}=\int f^{*}\left(\Delta w^{*} \mid \epsilon\right) \frac{\partial\left(\Delta w^{*}\right)}{\partial \pi} d G(\epsilon)
$$

where $f^{*}$ is the pdf of true wage changes. To make the exposition most stark, consider the following case:

$$
\frac{\partial\left(\Delta w^{*}\right)}{\partial \pi}=v \cdot \mathbf{1}\left(\Delta w^{*}>0\right)+\lambda \cdot \mathbf{1}\left(\Delta w^{*}<0\right)
$$

where $\mathbf{1}(\cdot)$ is the indicator function, and $v>0$ and $\lambda<0$. In this case, it is straightforward to show that:

$$
\frac{\partial P_{n}}{\partial \pi}=v \cdot \varphi(n)+\lambda \cdot[1-\varphi(n)]
$$

where $\varphi(n)=\left.\frac{\int_{0}^{\infty} f\left(\Delta w \mid \Delta w^{*}\right) d F\left(\Delta w^{*}\right)}{\int_{-\infty}^{\infty} f\left(\Delta w \mid \Delta w^{*}\right) d F\left(\Delta w^{*}\right)}\right|_{\Delta w=P_{n}} \in(0,1)$. Thus, the estimates of (18) report a weighted average of upper and lower tail effects, and are thus attenuated.

(ii) It is also true, however, that as $n \rightarrow 100$ (resp. 0) then $\varphi \rightarrow 1$ (resp. 0). Therefore, this attenuation vanishes for both sufficiently high and low percentiles.

(iii) Note that, since $\epsilon$ is independent of $\pi$, then $E(\Delta w \mid \pi)=E\left(\Delta w^{*} \mid \pi\right)$ : i.e. the mean conditional wage change is unaffected by measurement error. To complete the proof, note that, by definition:

$$
E(\Delta w \mid \pi) \equiv \frac{1}{100} \int P_{n} d n=E\left(\Delta w^{*} \mid \pi\right)
$$

\section{B Technical Details of Proposition 3}

The following lemma will turn out to be useful in what follows:

Lemma 2 If $\ln x \sim N\left(\mu, \sigma^{2}\right)$ then it follows that:

$$
\int_{\underline{x}}^{\bar{x}} x d F(x)=\exp \left[\mu+\frac{1}{2} \sigma^{2}\right]\left\{\Phi\left[\frac{\ln \bar{x}-\mu}{\sigma}-\sigma\right]-\Phi\left[\frac{\ln \underline{x}-\mu}{\sigma}-\sigma\right]\right\}
$$

where $\Phi(\cdot)$ is the c.d.f. of the standard Normal. 
Proof. Since $x$ is $\log$-Normally distributed, the p.d.f. of $x$ is given by $f(x)=\frac{1}{\sigma x} \phi\left(\frac{\ln x-\mu}{\sigma}\right)$, where $\phi(\cdot)$ is the p.d.f. of the standard Normal. It follows that:

$$
\int_{\underline{x}}^{\bar{x}} x d F(x)=\int_{\underline{x}}^{\bar{x}} x \frac{1}{\sigma x \sqrt{2 \pi}} \exp \left[-\frac{1}{2}\left(\frac{\ln x-\mu}{\sigma}\right)^{2}\right] d x
$$

Defining $z \equiv \ln x-\mu \Longrightarrow d x=\exp (\mu+z) d z$, we obtain:

$$
\int_{\underline{x}}^{\bar{x}} x d F(x)=\int_{\ln \underline{x}-\mu}^{\ln \bar{x}-\mu} \frac{1}{\sigma \sqrt{2 \pi}} \exp \left[\mu+z-\frac{1}{2 \sigma^{2}} z^{2}\right] d z
$$

Completing the square for the term in brackets and substituting back into the former expression:

$$
\begin{aligned}
\int_{\underline{x}}^{\bar{x}} x d F(x) & =\int_{\ln \underline{x}-\mu}^{\ln \bar{x}-\mu} \frac{1}{\sigma \sqrt{2 \pi}} \exp \left[\mu+\frac{1}{2} \sigma^{2}-\frac{1}{2}\left(\frac{z-\sigma^{2}}{\sigma}\right)^{2}\right] d z \\
& =\exp \left[\mu+\frac{1}{2} \sigma^{2}\right]\left\{\Phi\left[\frac{\ln \bar{x}-\mu}{\sigma}-\sigma\right]-\Phi\left[\frac{\ln \underline{x}-\mu}{\sigma}-\sigma\right]\right\}
\end{aligned}
$$

as required.

\section{B.1 Obtaining the functions $D(W, u(W))$ and $D(W, l(W))$}

We proceed by using the method of undetermined coefficients. We conjecture that $D(W, A)$ is of the form:

$$
D(W, A)=\alpha_{1} \frac{A}{W}+\alpha_{2}
$$

and verify that this will indeed be the case for $A=u(W)$ or $l(W)$, using Lemma 2 to solve out the integrals in (9). Following this method yields ${ }^{39}$ :

$$
\begin{aligned}
D(W, u(W)) & =(1+\pi) \frac{u(W)}{W}\left[\frac{\kappa_{1}-(1+c) \Phi_{1}}{1-\beta\left(\kappa_{1}-\Phi_{1}\right)}\right]-\frac{\kappa_{2}-\Phi_{2}}{1-\frac{\beta}{1+\pi}\left(\kappa_{2}-\Phi_{2}\right)} \\
D(W, l(W)) & =(1+\pi) \frac{l(W)}{W}\left[\frac{\Phi_{3}-(1+c) \kappa_{1}}{1-\beta\left(\Phi_{3}-\kappa_{1}\right)}\right]-\frac{\Phi_{4}-\kappa_{2}}{1-\frac{\beta}{1+\pi}\left(\Phi_{4}-\kappa_{2}\right)}
\end{aligned}
$$

where:

$$
\begin{array}{ll}
\Phi_{1}=\Phi\left[\frac{1}{\sigma}\left(-\ln G-\ln (1+\pi)+\frac{1}{2} \sigma^{2}\right)-\sigma\right] & \Phi_{2}=\Phi\left[\frac{1}{\sigma}\left(-\ln G-\ln (1+\pi)+\frac{1}{2} \sigma^{2}\right)\right] \\
\Phi_{3}=\Phi\left[\frac{1}{\sigma}\left(\ln G-\ln (1+\pi)+\frac{1}{2} \sigma^{2}\right)-\sigma\right] & \Phi_{4}=\Phi\left[\frac{1}{\sigma}\left(\ln G-\ln (1+\pi)+\frac{1}{2} \sigma^{2}\right)\right] \\
\kappa_{1}=\Phi\left[\frac{1}{\sigma}\left(-\ln (1+\pi)+\frac{1}{2} \sigma^{2}\right)-\sigma\right] & \kappa_{2}=\Phi\left[\frac{1}{\sigma}\left(-\ln (1+\pi)+\frac{1}{2} \sigma^{2}\right)\right]
\end{array}
$$

and we define $G \equiv \frac{u(W)}{l(W)}$, the geometric gap between the two trigger values for $A$.

\footnotetext{
${ }^{39}$ Technical details of this derivation are available on request from the author.
} 


\section{B.2 Obtaining the functions $u(W)$ and $l(W)$}

It is now straightforward to solve for the functions $u(W)$ and $l(W)$ by substituting the above (52) into the equations (8) to obtain after some algebra:

$$
\begin{aligned}
& u(W)=\left[\frac{1-\beta\left(\kappa_{1}-\Phi_{1}\right)}{1-\frac{\beta}{1+\pi}\left(\kappa_{2}-\Phi_{2}\right)} \cdot \frac{1}{1-c \beta \Phi_{1}}\right] \cdot W \\
& l(W)=\left[\frac{1-\beta\left(\Phi_{3}-\kappa_{1}\right)}{1-\frac{\beta}{1+\pi}\left(\Phi_{4}-\kappa_{2}\right)} \cdot \frac{1}{1+c-c \beta \Phi_{3}}\right] \cdot W
\end{aligned}
$$

These two equations clearly depend on $G \equiv \frac{u(W)}{l(W)}$, which is unknown so far. However, we can determine $G$ using our expressions for $u(W)$ and $l(W)$ above:

$$
\frac{u(W)}{l(W)} \equiv G=\frac{1+\pi-\beta\left(\Phi_{4}-\kappa_{2}\right)}{1+\pi-\beta\left(\kappa_{2}-\Phi_{2}\right)} \cdot \frac{1-\beta\left(\kappa_{1}-\Phi_{1}\right)}{1-\beta\left(\Phi_{3}-\kappa_{1}\right)} \cdot \frac{1+c-c \beta \Phi_{3}}{1-c \beta \Phi_{1}} \equiv T(G)
$$

Note that all the terms on the RHS of this equation are functions of $G$, and not of $W$. Obtaining the relevant value of $G$ requires solving for the fixed point(s) of the mapping defined by this equation. Given the relevant value of $G$, this implies that the $\Phi_{i} \mathrm{~s}, i=1, \ldots, 4$, will be given constants, as will the coefficients on $W$ in (54), and it follows that $u(W)=u \cdot W$ and $l(W)=l \cdot W$ as stated in the main text.

\section{B.3 Properties of the Map $T(G)$}

Simulations of the mapping $T(G)$ in $(55)$ reveal that, whilst there always exists at least one fixed point for $T(G)$, there is not, in general, a unique fixed point. Thus, in the case where there exists more than one fixed point, we need a criterion for identifying which fixed point value of $G$ maximizes the value function, which is provided by the following proposition:

Proposition 8 Where there exist multiple fixed points for the mapping $T(G)$, the wage policy that maximizes the value function is that associated with $G^{1} \equiv \min \{G: G=T(G)\}$.

Proof. Define the multiple fixed points of $T(G)$ as $G^{1}<G^{2}<G^{3}<\ldots$, and the associated value functions as $v^{1}, v^{2}, v^{3}, \ldots$. We claim that the following must be true:

$$
v^{1} \geq v^{2} \geq v^{3} \geq \ldots
$$

To see this, note first that a higher value of $G$ only serves to restrict the firm's choice of $W$ by widening the region in which wages are not changed. In particular, under a lower value of $G$, the firm can always choose a $W$ arbitrarily close to $W_{-1}$, and hence replicate the wage policy under a higher $G$, if it wishes. In general, though, the firm can do better than this under lower values of $G$. Thus the statement must hold. 
Figure 1: The Effort Function

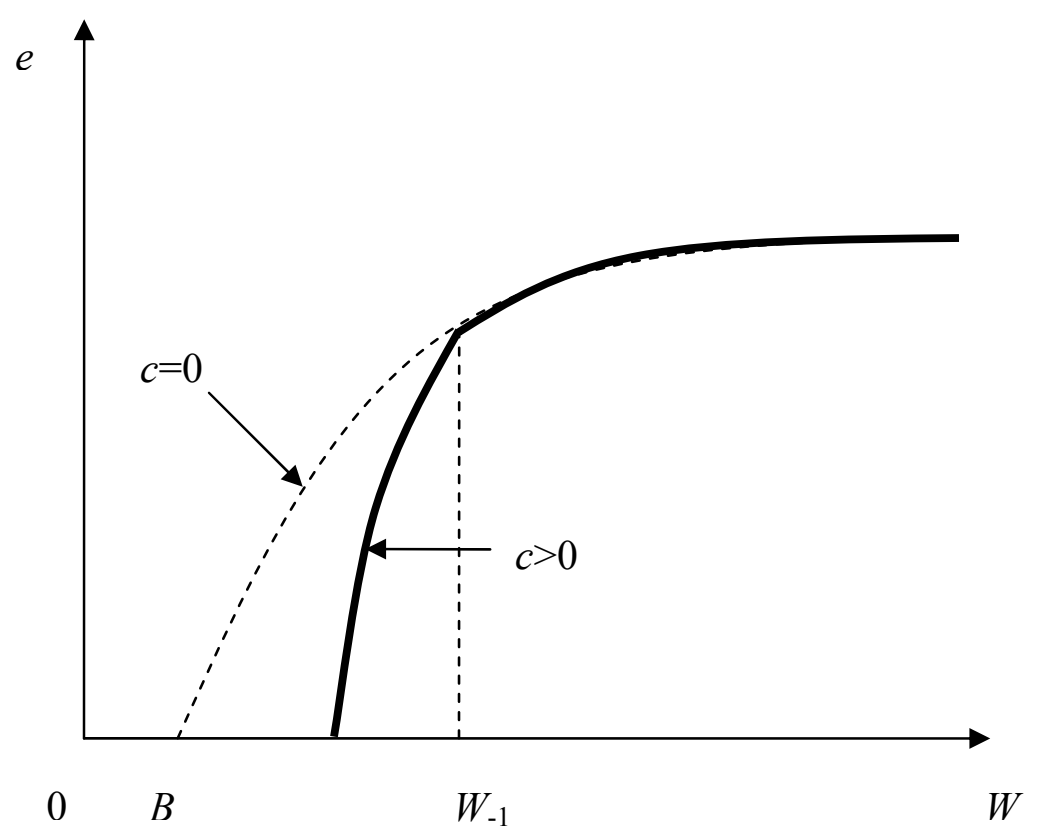

Figure 2: $f\left(\Delta \ln W \mid W_{-1}\right)$ implied by Theory

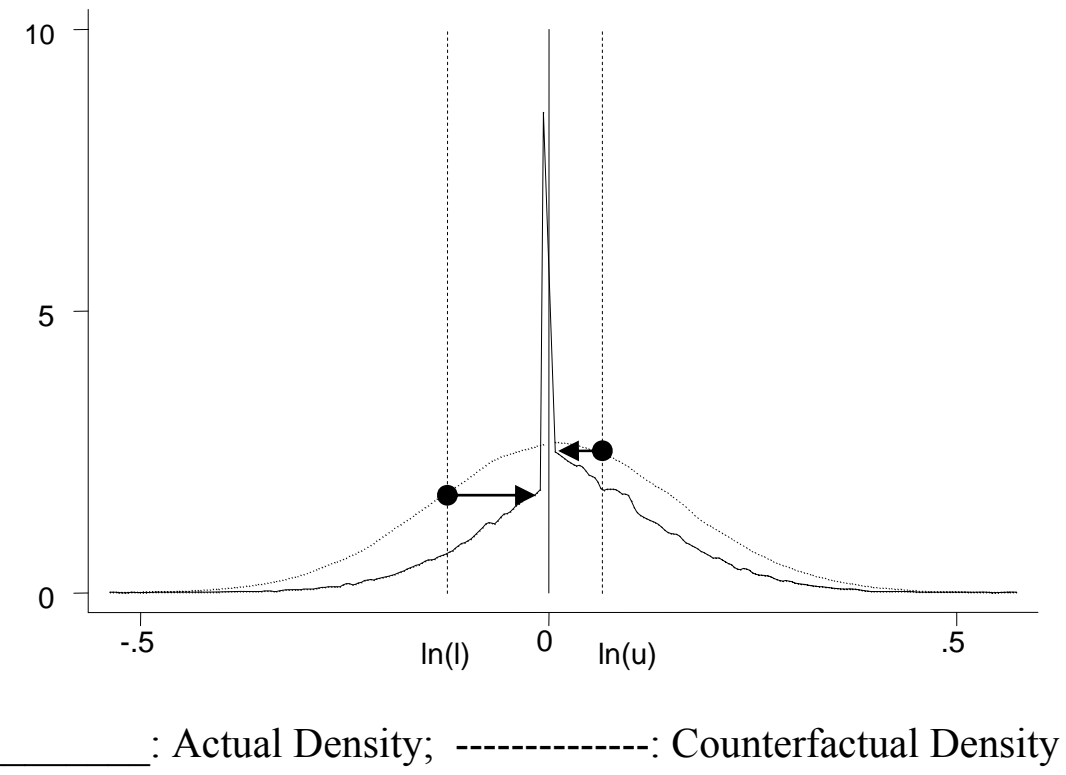


Figure 3: Properties of the Optimal Wage Policy Parameters

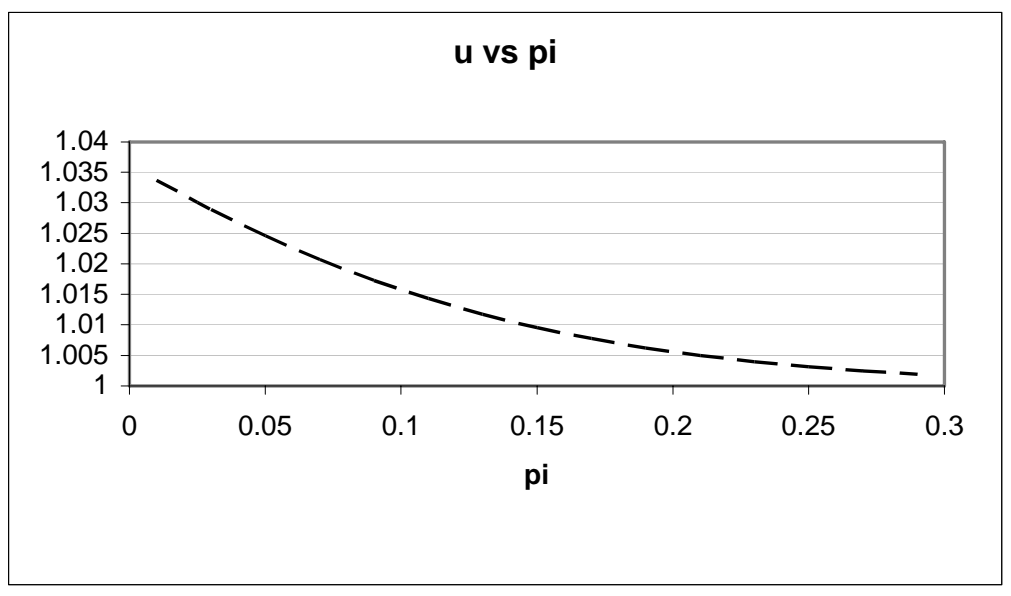

Figure 4: Theoretical $f\left(\Delta \ln W \mid W_{-1}\right)$ for Different Rates of Inflation

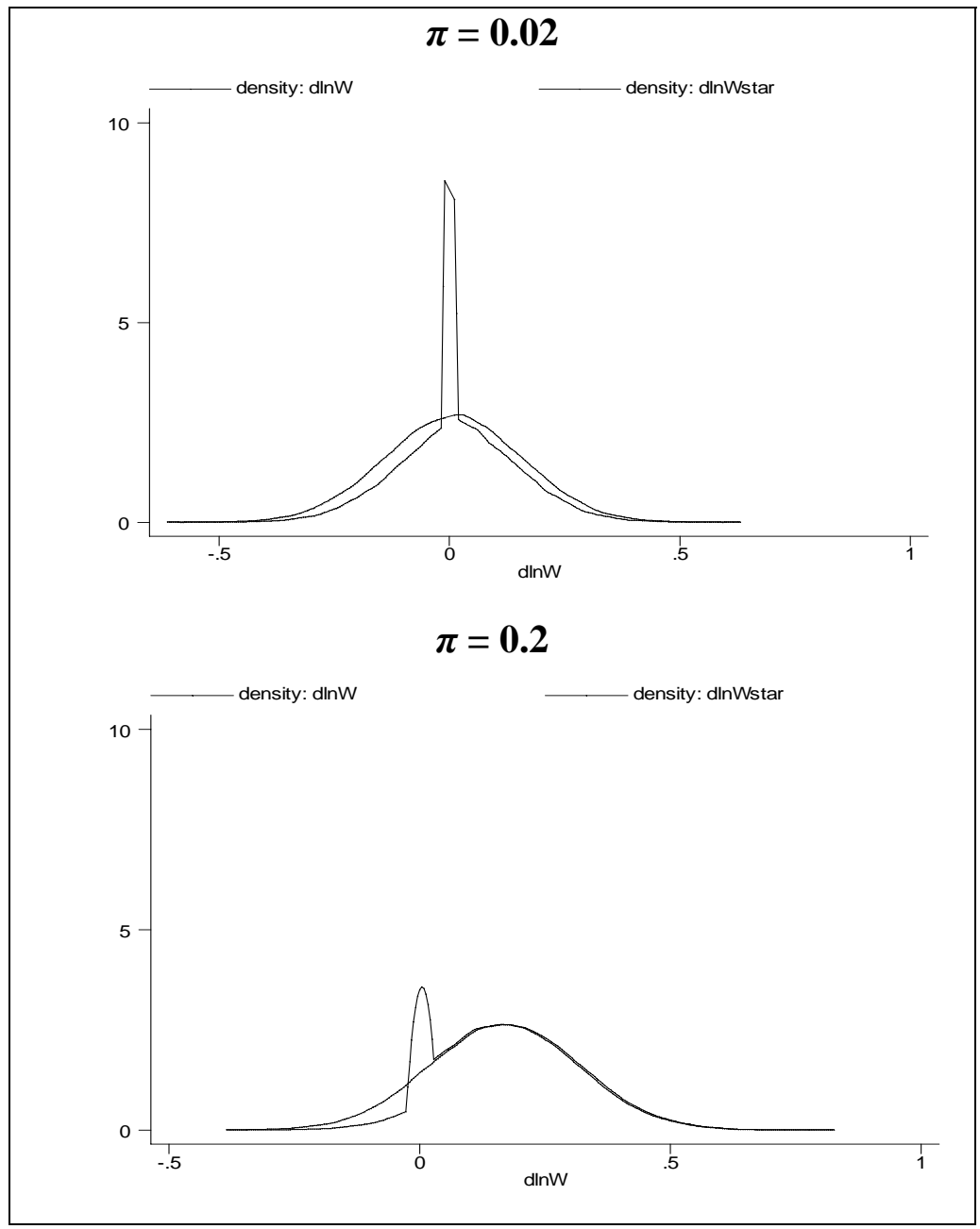


Figure 5: $f(\Delta \ln W)$ Implied by Theory when $\boldsymbol{\beta}=\mathbf{0}$

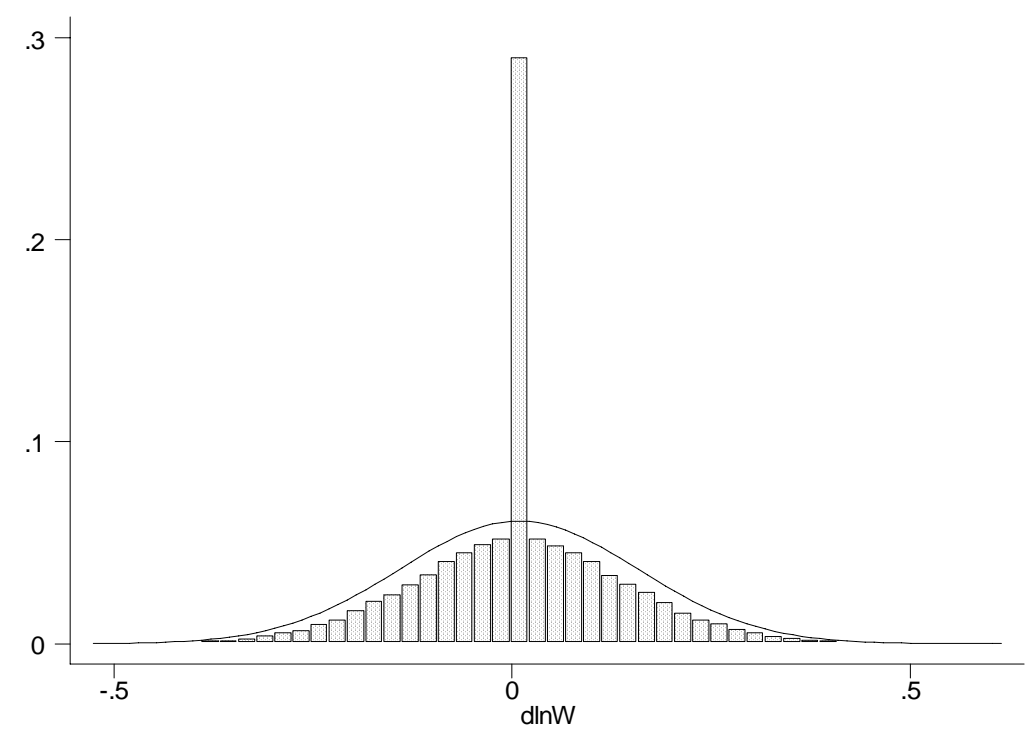

Notes:

Histogram: Actual Density; : Counterfactual Density

Simulations of $f(\Delta \ln W)$ predicted by model of 50,000 worker-firms after 10 periods.

Parameter values: $c=0.1, \beta=0, \pi=0.02, \sigma=0.15$.

\section{Figure 6: Overstatement of Costs of DNWR}

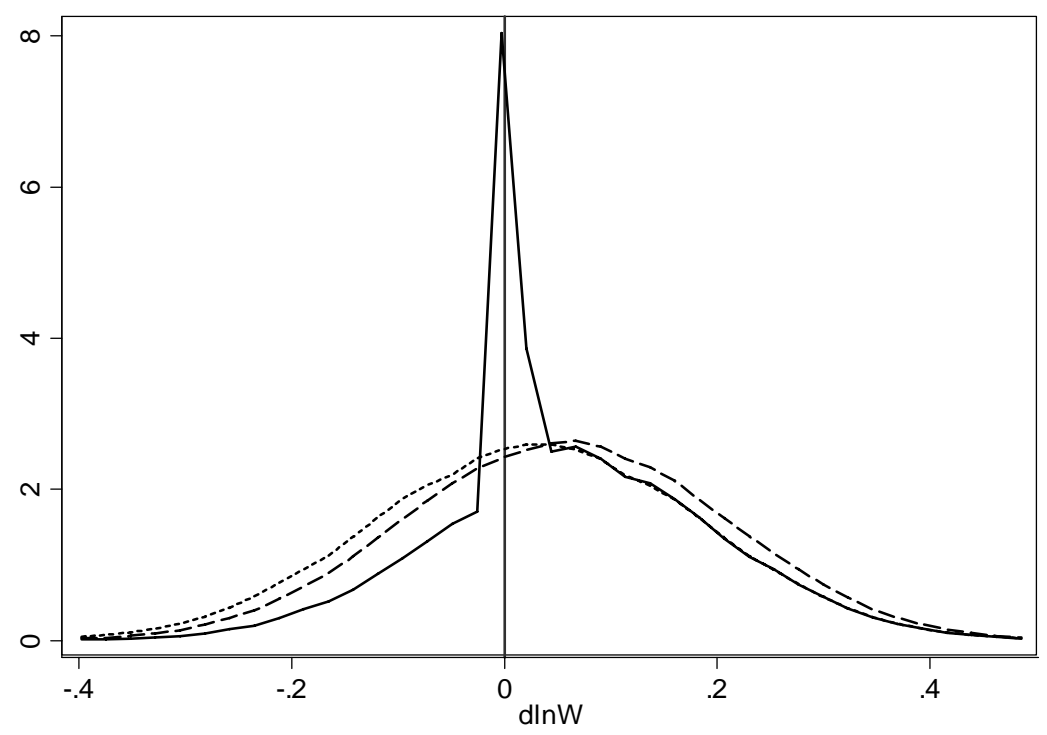

Actual Density, _ _ _ _ _ _ . True Counterfactual, .. 
Figure 7: Overstatement of the Increase in Labor Costs as a Fraction of the True Costs of DNWR

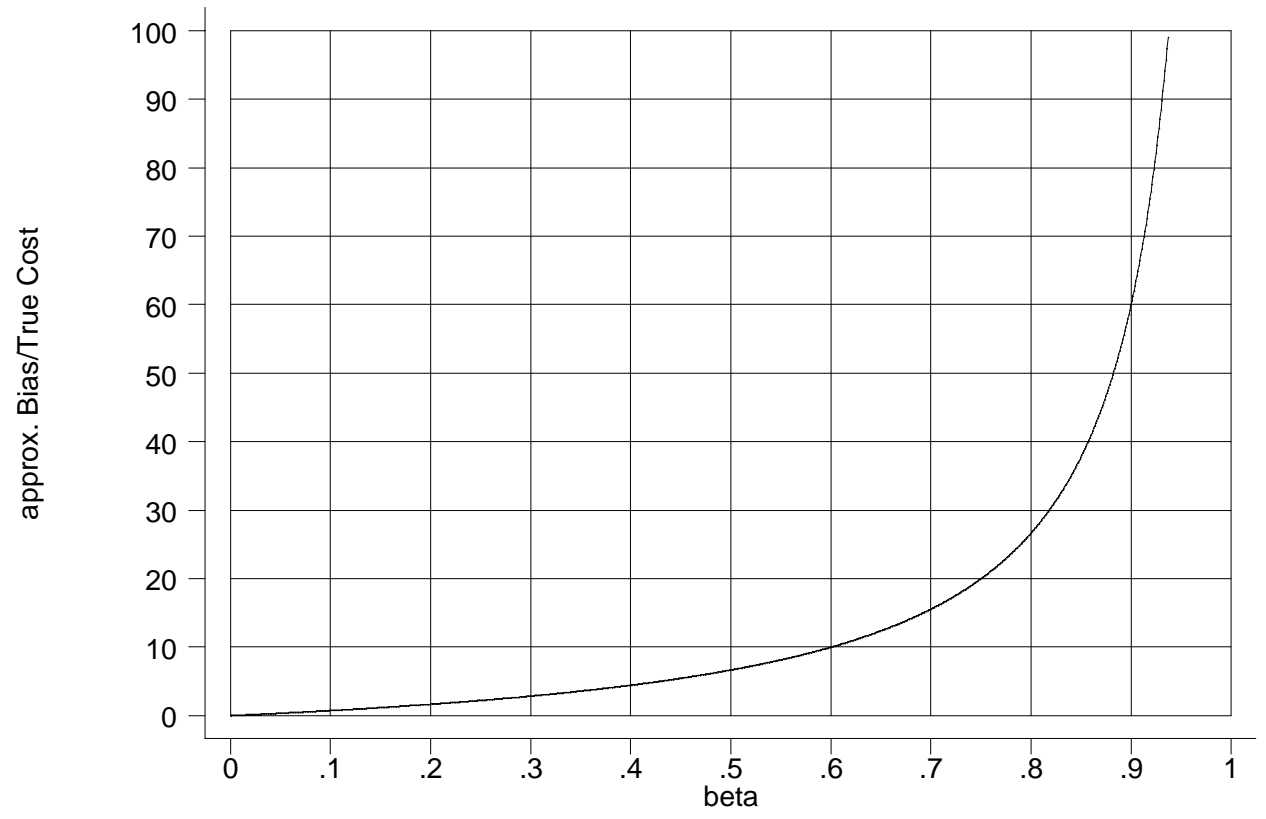

Figure 8: The Dramatic Increase in the Dispersion of Real Wage Changes after CPS survey redesign in 1994 (CPS)

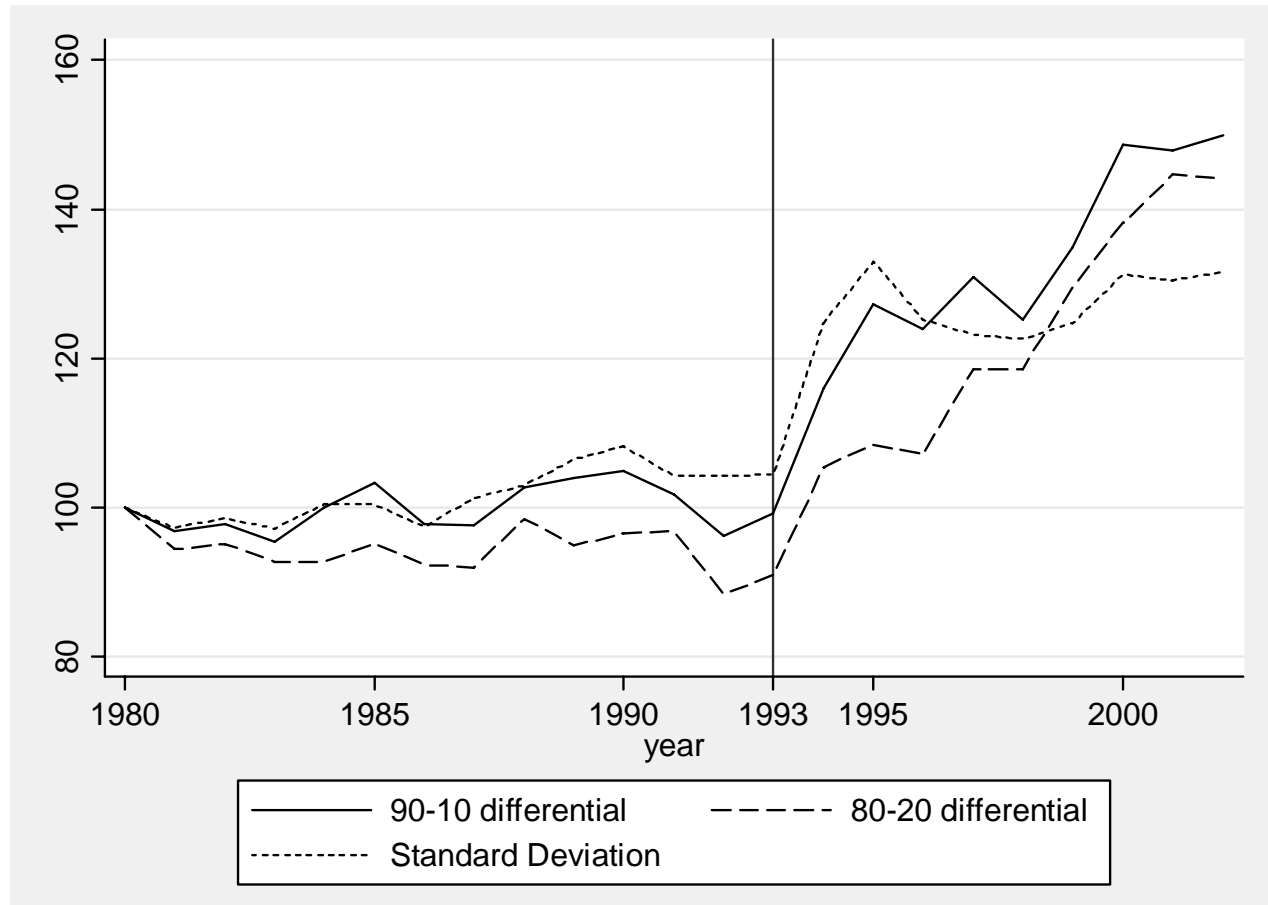

Notes:

We measure dispersion by the standard deviation and the 90-10 and 80-20 percentile differentials of log real wage changes. All measures of dispersion are normalised to equal 100 in 1980. 


\section{Figure 9: US \& UK Inflation over the Sample Periods}

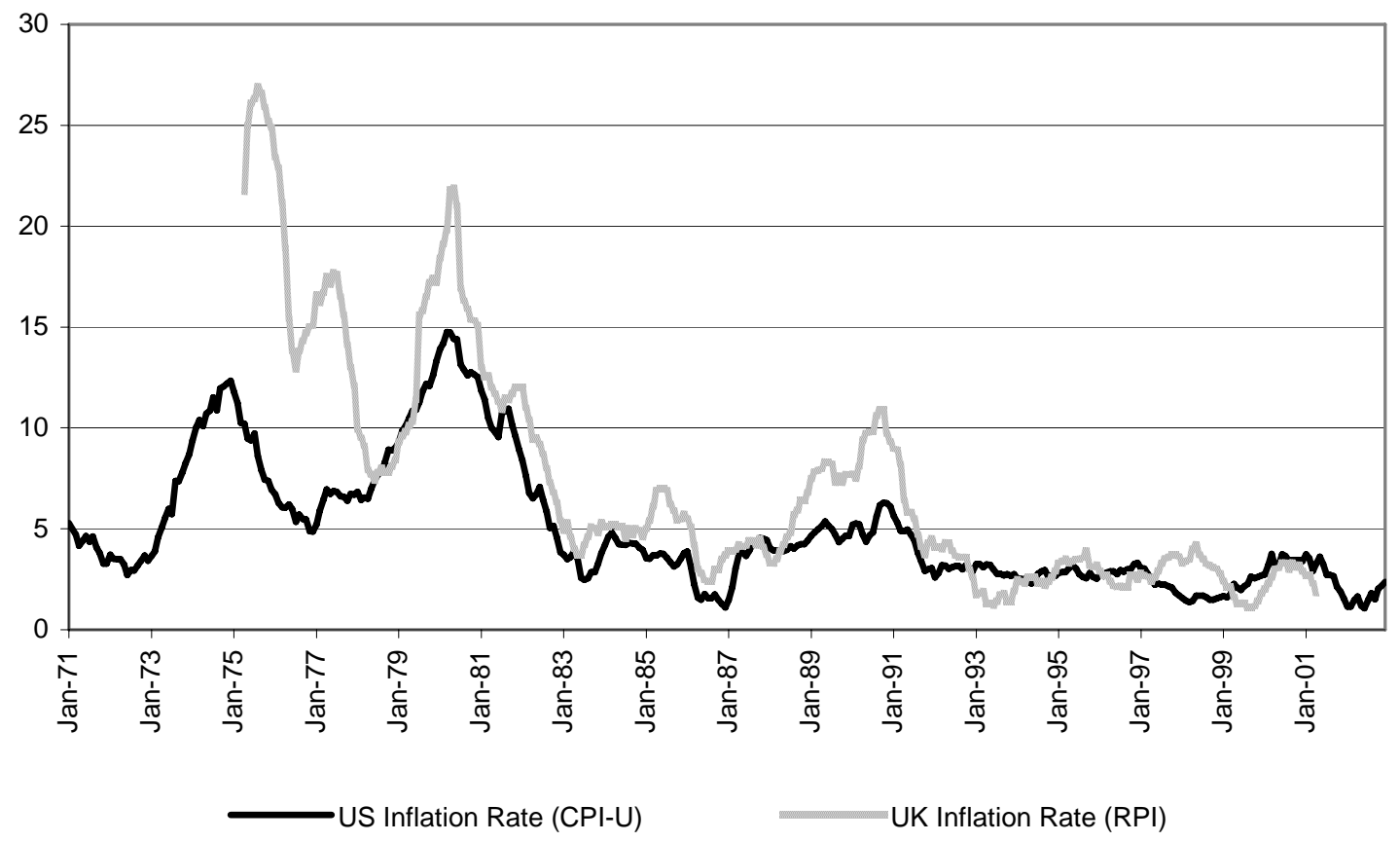

Source: US CPI data was obtained from http://data.bls.gov. UK RPI data was obtained from www.statistics.gov.uk/statbase.

\section{Figure 10: Density Estimates of Log Real Wage Change Distributions (PSID)}

a) Without Re-weighting

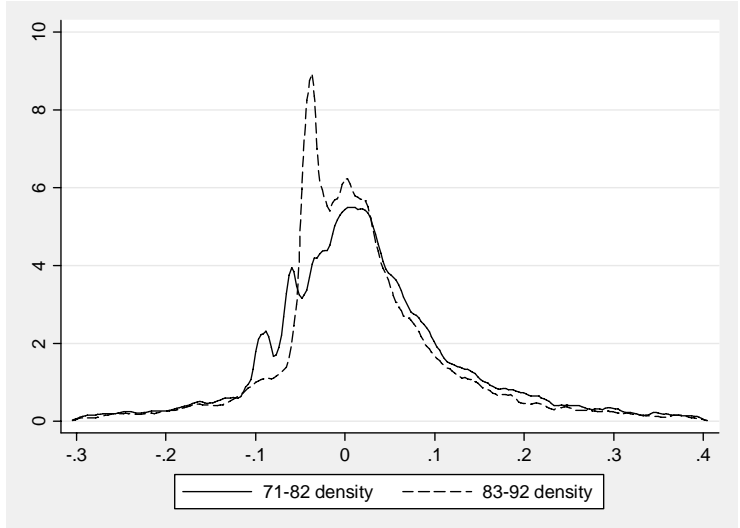

b) With Re-weighting ${ }^{\mathrm{b}}$

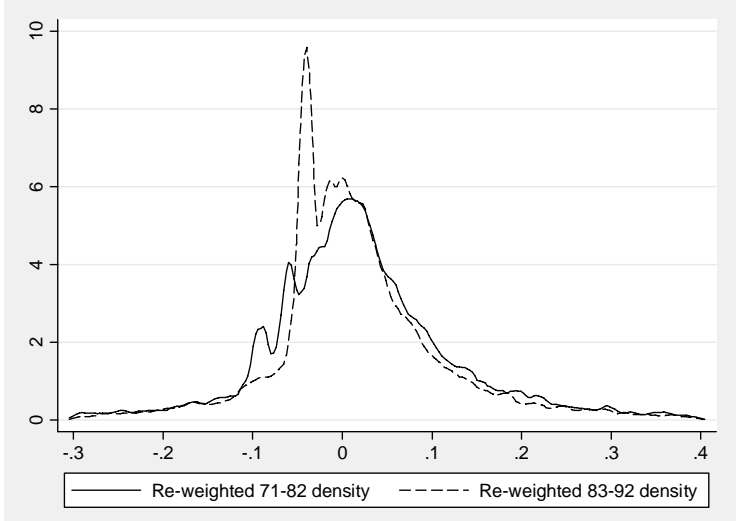

Notes:

a. Kernel density estimates using an Epanechnikov kernel, over 250 data points, and a bandwidth of 0.005 .

b. "Re-weighting" refers to the use of the DiNardo, Fortin \& Lemieux (1996) re-weighting technique to control for changes in age, age ${ }^{2}$, sex, education, 1-digit industry, 1-digit occupation, region, self employment, and tenure. 


\section{Figure 11: Density Estimates of Log Real Wage Change Distributions (NESPD)}

a) Without Re-weighting

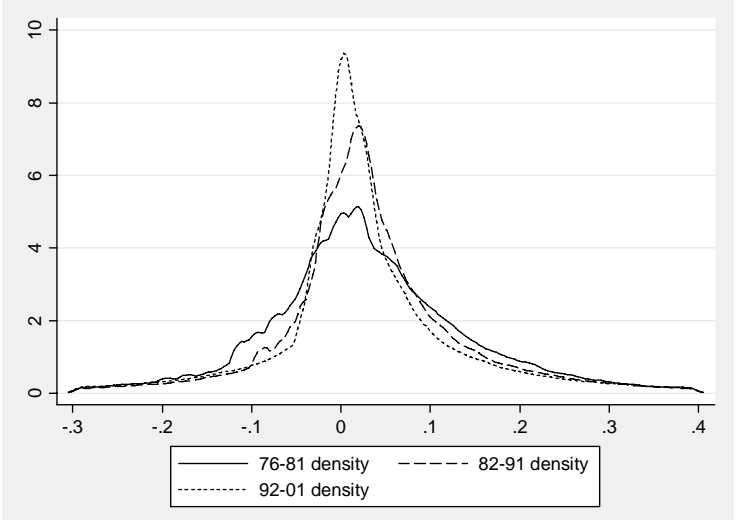

b) With Re-weighting

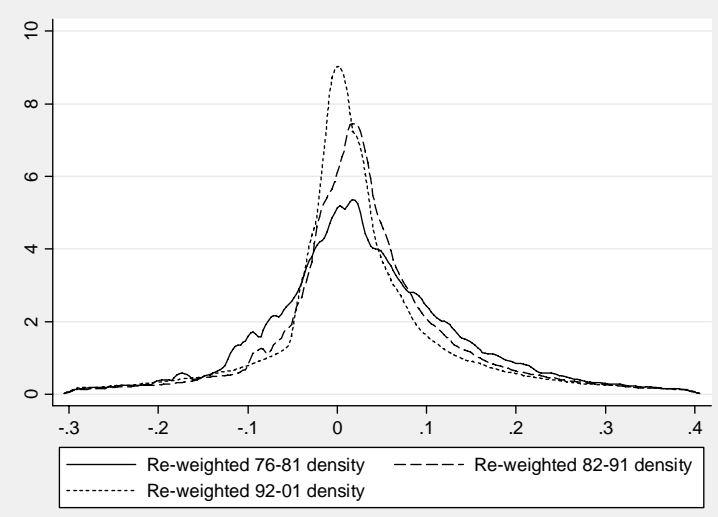

Notes:

a. Kernel density estimates using an Epanechnikov kernel, over 250 data points, and a bandwidth of 0.005 .

b. "Re-weighting" refers to the use of the DiNardo, Fortin \& Lemieux (1996) re-weighting technique to control for changes in age, age ${ }^{2}$, sex, region (including London dummy), 2-digit industry, 2-digit occupation, and major union coverage.

\section{Figure 12: Turnover Effects on the Distribution of Log Nominal Wage Changes for Job Stayers (NESPD)}

a) Without Re-Weighting

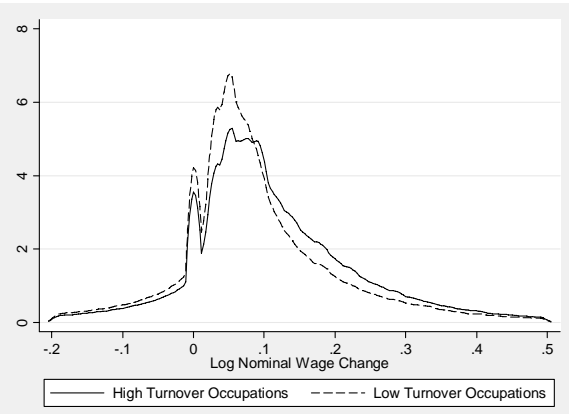

c) Re-Weighted - High Inflation

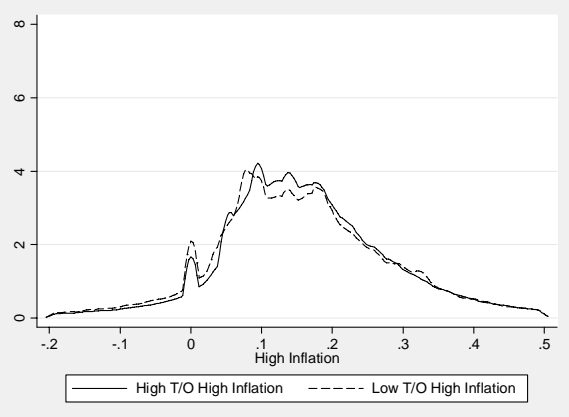

b) With Re-Weighting

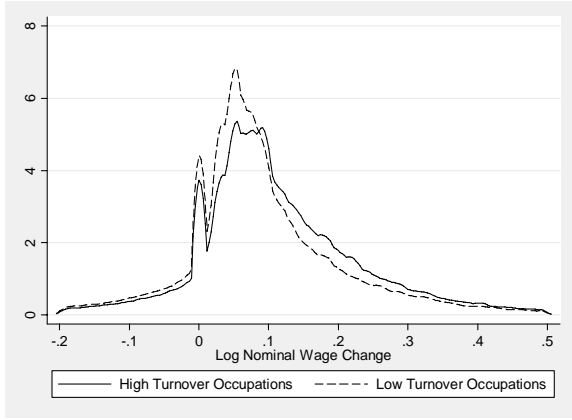

d) Re-Weighted - Low Inflation

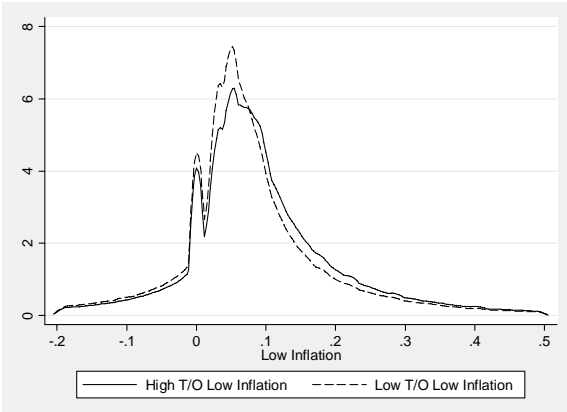

Notes:

a. Kernel density estimates using an Epanechnikov kernel, over 250 data points, and a bandwidth of 0.005 .

b. "Re-weighting" refers to the use of the DiNardo, Fortin \& Lemieux (1996) re-weighting technique to control for changes in adjusted lagged wages, age, age ${ }^{2}$, sex, region (including London dummy), 2-digit industry, 2-digit occupation, and major union coverage.

c. High turnover refers to occupations for which the fraction of job changers in any given year exceeds the median.

d. High inflation refers to years for which the inflation rate exceeded $10 \%$. 
Table 1: Descriptive Statistics of Wage Changes (CPS, PSID, NESPD)

\begin{tabular}{|c|c|c|c|c|c|c|c|c|c|c|c|}
\hline \multirow{2}{*}{ Year } & \multicolumn{4}{|c|}{ US Data: CPS } & \multicolumn{3}{|l|}{ PSID } & \multicolumn{4}{|c|}{ British Data: NESPD } \\
\hline & $\Pi$ & Obs. & $\Delta \mathrm{W}=0$ & $\Delta \omega<0$ & Obs. & $\Delta \mathrm{W}=0$ & $\Delta \omega<0$ & $\Pi$ & Obs. & $\Delta \mathrm{W}=0$ & $\Delta \omega<0$ \\
\hline 1971 & 4.4 & & & & 1,520 & 10.39 & 34.41 & & & & \\
\hline 1972 & 3.0 & & & & 1,527 & 11.59 & 32.35 & & & & \\
\hline 1973 & 6.3 & & & & 1,599 & 8.88 & 46.34 & & & & \\
\hline 1974 & 10.0 & & & & 1,676 & 8.35 & 56.74 & & & & \\
\hline 1975 & 8.3 & & & & 1,733 & 7.39 & 42.07 & & & & \\
\hline 1976 & 5.7 & & & & 1,471 & 7.48 & 34.33 & 18.9 & 60,318 & 0.67 & 41.00 \\
\hline 1977 & 6.4 & & & & 1,468 & 8.65 & 36.72 & 17.5 & 64,838 & 1.43 & 77.64 \\
\hline 1978 & 6.8 & & & & 1,605 & 7.35 & 37.57 & 7.9 & 66,168 & 2.15 & 33.73 \\
\hline 1979 & 9.6 & & & & 1,704 & 6.51 & 51.35 & 10.1 & 65,619 & 2.33 & 38.39 \\
\hline 1980 & 11.2 & 25,626 & 5.70 & 53.39 & 1,756 & 4.38 & 52.51 & 21.8 & 66,574 & 0.44 & 46.81 \\
\hline 1981 & 9.5 & 28,343 & 5.79 & 48.07 & 1,746 & 7.22 & 50.29 & 12 & 70,431 & 2.62 & 40.53 \\
\hline 1982 & 6.1 & 27,426 & 10.41 & 45.76 & 1,664 & 8.17 & 38.58 & 9.4 & 75,745 & 3.01 & 49.34 \\
\hline 1983 & 4.2 & 26,521 & 12.73 & 45.99 & 1,606 & 14.51 & 44.46 & 4 & 77,910 & 2.06 & 19.93 \\
\hline 1984 & 4.3 & 26,675 & 12.76 & 46.29 & 1,621 & 12.95 & 46.33 & 5.2 & 75,652 & 5.09 & 41.62 \\
\hline 1985 & 3.6 & 13,122 & 12.28 & 43.72 & 1,702 & 11.16 & 41.07 & 6.9 & 75,311 & 1.69 & 50.80 \\
\hline 1986 & 1.9 & 6,935 & 13.67 & 40.63 & 1,830 & 15.30 & 42.51 & 3 & 74,487 & 1.39 & 18.88 \\
\hline 1987 & 3.7 & 27,348 & 13.68 & 45.94 & 1,801 & 15.16 & 49.53 & 4.2 & 74,848 & 2.52 & 24.97 \\
\hline 1988 & 4.1 & 26,825 & 12.59 & 46.43 & 1,848 & 15.42 & 50.87 & 3.9 & 73,440 & 1.55 & 20.57 \\
\hline 1989 & 4.8 & 26,736 & 11.99 & 47.90 & 1,863 & 13.96 & 53.30 & 8 & 72,278 & 2.13 & 44.91 \\
\hline 1990 & 5.4 & 28,045 & 11.14 & 49.11 & 1,815 & 12.01 & 54.66 & 9.4 & 70,752 & 2.49 & 50.33 \\
\hline 1991 & 4.2 & 28,688 & 11.61 & 46.52 & 2,441 & 13.93 & 49.77 & 6.4 & 72,065 & 2.75 & 26.40 \\
\hline 1992 & 3.0 & 28,521 & 13.43 & 44.94 & 2,441 & 16.39 & 45.60 & 4.3 & 76,335 & 4.87 & 30.87 \\
\hline 1993 & 3.0 & 28,468 & 13.25 & 45.73 & & & & 1.3 & 78,171 & 6.95 & 27.91 \\
\hline 1994 & 2.6 & 26,584 & 11.88 & 44.49 & & & & 2.6 & 78,167 & 6.36 & 48.14 \\
\hline 1995 & 2.8 & 10,227 & 12.20 & 45.32 & & & & 3.3 & 79,644 & 5.55 & 51.37 \\
\hline 1996 & 3.0 & 8,458 & 11.46 & 44.68 & & & & 2.4 & 82,489 & 1.53 & 32.31 \\
\hline 1997 & 2.3 & 25,386 & 10.67 & 41.53 & & & & 2.4 & 80,221 & 1.71 & 33.52 \\
\hline 1998 & 1.6 & 25,255 & 10.31 & 38.00 & & & & 4 & 76,999 & 4.08 & 51.19 \\
\hline 1999 & 2.2 & 25,489 & 9.80 & 41.02 & & & & 1.6 & 77,227 & 4.38 & 25.93 \\
\hline 2000 & 3.4 & 25,215 & 9.68 & 44.19 & & & & 3 & 76,806 & 4.35 & 39.69 \\
\hline 2001 & 2.9 & 24,574 & 9.32 & 42.65 & & & & 1.8 & 79,689 & 0.00 & 32.69 \\
\hline 2002 & 1.6 & 26,575 & 10.32 & 42.38 & & & & & & & \\
\hline
\end{tabular}

Notes:

" $\Pi$ " denotes the rate of inflation in a given year. This is measured by the CPI-U-X1 for the US, and the RPI for the UK

"Obs." Refers to the number of non-missing wage change observations each year.

" $\Delta \mathrm{W}=0$ " reports the percentage of nominal wage changes each year that are exactly zero.

" $\Delta \omega<0$ " reports the percentage of real wage cuts implemented each year. 
Table 2: Summary Statistics (CPS, PSID, NESPD)

(a) CPS :

Obs

Mean

Std. Dev.

Min

Max

\begin{tabular}{|l|c|c|c|c|c|}
\hline Change in log real wage & 547042 & 0.025061 & 0.310781 & -5.72642 & 4.562072 \\
\hline Age & 547042 & 38.01381 & 12.52692 & 16 & 65 \\
\hline Female & 547042 & 0.501651 & 0.499998 & $\odot$ & 1 \\
\hline Education: & & & & & \\
\hline < High School & 546516 & 0.175773 & $\odot .380628$ & $\odot$ & 1 \\
\hline High School & 546516 & 0.451021 & 0.497596 & $\odot$ & 1 \\
\hline Some College & 546516 & 0.287882 & $\odot .452776$ & $\odot$ & 1 \\
\hline College Degree & 546516 & 0.071936 & $\odot .258382$ & $\odot$ & 1 \\
\hline Advanced Degree & 546516 & 0.013388 & 0.114931 & $\odot$ & 1 \\
\hline Metropolitan area & 521083 & 0.710509 & 0.453527 & $\odot$ & 1 \\
\hline Non-white & 547042 & 0.204385 & $\odot .403252$ & $\odot$ & 1 \\
\hline Self-employed & 546877 & 0.000104 & 0.010209 & & \\
\hline
\end{tabular}

(b) PSID :

\begin{tabular}{|c|c|c|c|c|c|}
\hline Change in log real wage & 33283 & 0.022087 & 0.337482 & -3.72463 & 4.619859 \\
\hline Age & 33283 & 38.24457 & 11.53739 & 18 & 65 \\
\hline Female & 33283 & 0.196617 & 0.397446 & $\odot$ & 1 \\
\hline \multicolumn{6}{|l|}{ Education: } \\
\hline $0-5$ grades & 30671 & 0.036256 & 0.186929 & $\odot$ & 1 \\
\hline 6-8 grades & 30671 & 0.114375 & 0.318272 & $\Theta$ & 1 \\
\hline 9-11 grades & 30671 & 0.218382 & 0.413155 & $\odot$ & 1 \\
\hline 12 grades & 30671 & 0.448469 & 0.497346 & $\odot$ & 1 \\
\hline Some College & 30671 & 0.130253 & 0.336587 & $\Theta$ & 1 \\
\hline College degree & 30671 & 0.040201 & 0.196433 & $\odot$ & 1 \\
\hline Advanced degree & 30671 & 0.012064 & 0.109171 & $\theta$ & 1 \\
\hline \multicolumn{6}{|l|}{ Tenure: } \\
\hline$[1,1.5]$ years & 30536 & 0.092907 & 0.290306 & $\theta$ & 1 \\
\hline$(1.5,3.5)$ years & 30536 & 0.204546 & 0.403376 & $\Theta$ & 1 \\
\hline$[3.5,9.5)$ years & 30536 & 0.354008 & 0.47822 & $\theta$ & 1 \\
\hline$[9.5,19.5)$ years & 30536 & 0.236999 & 0.425249 & $\odot$ & 1 \\
\hline 19.5 years + & 30536 & 0.111541 & 0.314805 & $\odot$ & 1 \\
\hline Self-employed & 33257 & 0.014313 & 0.118779 & $\odot$ & 1 \\
\hline
\end{tabular}

(c) NESPD :

\begin{tabular}{|l|c|c|c|c|c|}
\hline Change in log real wage & 1922184 & 0.026539 & 0.190503 & -9.9292 & 9.757886 \\
\hline Age & 1922184 & 41.01464 & 11.85092 & 16 & 65 \\
\hline Female & 1922184 & 0.409069 & 0.491662 & 0 & 1 \\
\hline Major union coverage & 1922029 & 0.426511 & 0.49457 & $\odot$ & 1 \\
\hline London dummy & 1919091 & 0.144433 & 0.351528 & $\odot$ & 1 \\
\hline
\end{tabular}

Notes:

CPS sample also contains 2-digit industry classifications, and 50 regional dummies.

PSID sample also contains 1-digit industry and 1-digit occupation classifications, and 6 region dummies.

NESPD sample also contains 2-digit industry and 2-digit occupation classifications, and 10 region dummies. Major union coverage variable does not include more disaggregated union agreements. 
Table 3: Regressions of Percentiles of Real Wage Changes on the Rate of Inflation and Controls (CPS, 1980 - 2002)

\begin{tabular}{|c|c|c|c|c|c|c|}
\hline \multirow{2}{*}{ Percentile } & \multicolumn{6}{|c|}{ Coefficient on Inflation Rate ${ }^{a}$} \\
\hline & \multicolumn{2}{|c|}{ No Controls ${ }^{b}$} & \multicolumn{2}{|c|}{ Aggregate Controls ${ }^{c}$} & \multicolumn{2}{|c|}{ Full Controls ${ }^{d}$} \\
\hline $10^{\text {th }}$ & -0.062 & {$[0.134]$} & $\odot .06$ & {$[0.148]$} & -0.067 & {$[0.151]$} \\
\hline $20^{\text {th }}$ & -0.254 & {$[0.070] * * *$} & -0.157 & {$[\odot . \odot 9 \odot]^{*}$} & -0.15 & {$[\odot .091]$} \\
\hline $30^{\text {th }}$ & -0.326 & {$[0.074] * * *$} & -0.275 & {$[0.074] * * *$} & -0.366 & {$[\odot .068]^{* * *}$} \\
\hline $40^{\text {th }}$ & 0.04 & {$[0.040]$} & $\odot .049$ & {$[0.043]$} & 0.035 & {$[\odot .038]$} \\
\hline $60^{\text {th }}$ & 0.053 & {$[0.024]^{*}$ * } & 0.053 & {$[0.025]^{* *}$} & 0.045 & {$[\odot .028]$} \\
\hline $70^{\text {th }}$ & 0.123 & {$[0.050]^{* *}$} & $\odot .123$ & {$[0.051]^{* *}$} & 0.127 & {$[\odot .049]^{* *}$} \\
\hline $80^{\text {th }}$ & 0.178 & {$[\odot .093]^{*}$} & $\odot .198$ & {$[0.100]^{*}$} & 0.154 & {$[0.092]$} \\
\hline $90^{\text {th }}$ & 0.162 & {$[0.159]$} & 0.262 & {$[0.172]$} & 0.373 & {$[0.131]^{* * *}$} \\
\hline $\begin{array}{l}\text { Lower Tail } \\
\text { Losses }\end{array}$ & & $.98 \%$ & & $.37 \%$ & & $.10 \%$ \\
\hline Upper Tail Gains & & $.98 \%$ & & $.45 \%$ & & $.57 \%$ \\
\hline$\underset{\text { DNWR }^{\mathrm{e}}}{\uparrow} \operatorname{in} \Delta \bar{w}$ due to & & $\odot \%$ & & $.07 \%$ & & $.47 \%$ \\
\hline
\end{tabular}

Notes:

a. Reports Least Squares estimates (weighted by region size) of real wage change percentiles on the rate of inflation and controls.

b. Includes a dummy for the years 1994 onwards to control for the increase in dispersion of real wage changes following introduction of CAPI.

c. As b, but includes additional controls for the absolute change in the rate of inflation, and the contemporaneous and lagged state unemployment rate.

d. As c, but uses real wage change percentiles re-weighted for changes in age, age ${ }^{2}$, sex, race, region (including metropolitan dummy), 2digit industry, education, public sector employment, and self-employment.

e. Predicted effect on real wage growth of a change in inflation from 22\% (maximum NESPD sample inflation, 1980) down to $1.3 \%$ (minimum NESPD sample inflation, 1993). Computed from estimation of 99 percentile regressions of the form summarised in the Table using the method outlined in the main text.

f. Standard errors in brackets: robust to non-independence within years.

g. $*$ significant at the $10 \%$ level; ** significant at the $5 \%$ level; *** significant at the $1 \%$ level. 
Table 4: Regressions of Percentiles of Real Wage Changes on the Rate of Inflation and Controls (PSID, 1971 - 92)

\begin{tabular}{|c|c|c|c|c|c|c|}
\hline \multirow{2}{*}{ Percentile } & \multicolumn{6}{|c|}{ Coefficient on Inflation Rate ${ }^{a}$} \\
\hline & \multicolumn{2}{|c|}{ No Controls } & \multicolumn{2}{|c|}{ Aggregate Controls ${ }^{b}$} & \multicolumn{2}{|c|}{ Full Controls ${ }^{c}$} \\
\hline $10^{\text {th }}$ & -0.228 & {$[0.076] * * *$} & -0.227 & {$[0.077] * * *$} & -0.236 & {$[0.100]^{* *}$} \\
\hline $20^{\text {th }}$ & -0.596 & {$[0.090] * * *$} & -0.57 & {$[0.099] * * *$} & -0.585 & {$[0.100] * * *$} \\
\hline $30^{\text {th }}$ & 0.018 & {$[0.034]$} & 0.003 & {$[0.041]$} & -0.026 & {$[0.040]$} \\
\hline $40^{\text {th }}$ & 0.017 & {$[\odot .024]$} & 0.016 & {$[\odot .027]$} & 0.012 & {$[0.030]$} \\
\hline $60^{\text {th }}$ & $\odot .029$ & {$[0.023]$} & 0.027 & {$[\odot .027]$} & 0.015 & {$[0.033]$} \\
\hline $70^{\text {th }}$ & $\odot .096$ & {$[\odot . \odot 47]^{*}$} & 0.11 & {$[\odot .051] * *$} & 0.066 & {$[0.054]$} \\
\hline $80^{\text {th }}$ & $\odot .177$ & {$[\odot .074]^{* *}$} & $\odot .173$ & {$[\odot .081]^{* *}$} & 0.16 & {$[\odot .081]^{*}$} \\
\hline $90^{\text {th }}$ & 0.313 & {$[0.123]^{* *}$} & 0.33 & {$[0.122]^{* *}$} & 0.301 & {$[0.118]^{* *}$} \\
\hline $\begin{array}{l}\text { Lower Tail } \\
\text { Losses }\end{array}$ & \multicolumn{2}{|c|}{$+1.05 \%$} & \multicolumn{2}{|c|}{$+1.13 \%$} & \multicolumn{2}{|c|}{$+1.18 \%$} \\
\hline Upper Tail Gains & \multicolumn{2}{|c|}{$-0.90 \%$} & \multicolumn{2}{|c|}{$-1.11 \%$} & \multicolumn{2}{|c|}{$-1.04 \%$} \\
\hline$\underset{\text { DNWR }^{\mathrm{d}}}{\uparrow}$ in $\Delta \bar{w}$ due to & \multicolumn{2}{|c|}{$+0.15 \%$} & \multicolumn{2}{|c|}{$+\odot .02 \%$} & \multicolumn{2}{|c|}{$+0.14 \%$} \\
\hline
\end{tabular}

Notes:

a. Reports Least Squares estimates (weighted by region size) of real wage change percentiles on the rate of inflation and controls.

b. Controls for the absolute change in the rate of inflation.

c. As b, but uses real wage change percentiles re-weighted for changes in age, age ${ }^{2}$, sex, education, 1-digit industry, 1-digit occupation, region, self employment, and tenure.

d. Predicted effect on real wage growth of a change in inflation from 22\% (maximum NESPD sample inflation, 1980) down to $1.3 \%$ (minimum NESPD sample inflation, 1993). Computed from estimation of 97 percentile regressions of the form summarised in the Table using the method outlined in the main text - bottom and top percentiles are trimmed away as these yield extreme results.

e. Standard errors in brackets: robust to non-independence within years.

f. * significant at the $10 \%$ level; ** significant at the $5 \%$ level; *** significant at the $1 \%$ level. 
Table 5: Regressions of Percentiles of Real Wage Changes on the Rate of Inflation and Controls (NESPD, 1976 - 2001)

\begin{tabular}{|c|c|c|c|c|c|c|}
\hline \multirow{2}{*}{ Percentile } & \multicolumn{6}{|c|}{ Coefficient on Inflation Rate ${ }^{a}$} \\
\hline & \multicolumn{2}{|c|}{ No Controls ${ }^{b}$} & \multicolumn{2}{|c|}{ Aggregate Controls ${ }^{c}$} & \multicolumn{2}{|c|}{ Full Controls ${ }^{d}$} \\
\hline $10^{\text {th }}$ & -0.138 & {$[0.061] * *$} & $-\odot .057$ & {$[0.061]$} & -0.103 & {$[0.068]$} \\
\hline $20^{\text {th }}$ & $-\odot .286$ & {$[0.033] * * *$} & -0.227 & {$[0.018]^{* * *}$} & -0.239 & {$[0.021] * * *$} \\
\hline $30^{\text {th }}$ & $-\odot .197$ & {$[0.023]^{* * *}$} & -0.149 & {$[0.020]^{* * *}$} & -0.143 & {$[0.023]^{* * *}$} \\
\hline $40^{\text {th }}$ & -0.101 & {$[0.016] * * *$} & -0.089 & {$[0.016]^{* * *}$} & -0.089 & {$[0.011] * * *$} \\
\hline $60^{\text {th }}$ & 0.088 & {$[0.008] * * *$} & $\odot .076$ & {$[0.009] * * *$} & $\odot .074$ & {$[0.008]^{* * *}$} \\
\hline $70^{\text {th }}$ & 0.165 & {$[0.015]^{* * *}$} & 0.147 & {$[0.017]^{* * *}$} & $\odot .148$ & {$[\odot .014] * * *$} \\
\hline $80^{\text {th }}$ & 0.206 & {$[\odot .028] * * *$} & $\odot .176$ & {$[0.027]^{* * *}$} & $\odot .172$ & {$[0.023]^{* * *}$} \\
\hline $90^{\text {th }}$ & 0.117 & {$[0.053]^{* *}$} & 0.066 & {$[0.047]$} & 0.103 & {$[\odot .043]^{* *}$} \\
\hline $\begin{array}{l}\text { Lower Tail } \\
\text { Losses }\end{array}$ & & $1.26 \%$ & & 0. $71 \%$ & & $1.16 \%$ \\
\hline $\begin{array}{l}\text { Upper Tail } \\
\text { Gains }\end{array}$ & & $\odot .96 \%$ & & $0.67 \%$ & & $1.04 \%$ \\
\hline $\begin{array}{l}\uparrow \text { in } \Delta \bar{w} \text { due } \\
\text { to } \operatorname{DNWR}^{\mathrm{e}}\end{array}$ & & $\odot .30 \%$ & & 0. . $04 \%$ & & $\odot .13 \%$ \\
\hline
\end{tabular}

Notes:

a. Reports Least Squares estimates (weighted by region size) of real wage change percentiles on the rate of inflation and controls.

b. Includes a dummy for the year 1977 to control for the dramatic fall in real wage growth due to the incomes policies implemented in the UK at that time.

c. As b, but includes additional controls for the absolute change in the rate of inflation, and the contemporaneous and lagged regional unemployment rate.

d. As c, but uses real wage change percentiles re-weighted for changes in age, age ${ }^{2}$, sex, region (including London dummy), 2-digit industry, 2-digit occupation, and major union coverage.

e. Predicted effect on real wage growth of a change in inflation from 22\% (maximum NESPD sample inflation, 1980) down to $1.3 \%$ (minimum NESPD sample inflation, 1993). Computed from estimation of 99 percentile regressions of the form summarised in the Table using the method outlined in the main text.

f. Standard errors in brackets: robust to non-independence within years.

g. * significant at the $10 \%$ level; ** significant at the $5 \%$ level; *** significant at the $1 \%$ level. 
Table 6: Effect of Turnover on Percentiles of Nominal Wage Increases for Job Stayers (NESPD)

\begin{tabular}{|c|c|c|c|c|c|}
\hline \multirow{2}{*}{ Percentile } & \multirow{2}{*}{$\frac{(1)}{\tau}$} & \multirow{2}{*}{$\frac{(2)}{\tau}$} & \multicolumn{3}{|c|}{$(3)^{c}$} \\
\hline & & & $\tau$ & I & $\pi * \tau$ \\
\hline $60^{\text {th }}$ & $\begin{array}{c}0.023 \\
{[\odot . \odot \odot 2]^{* * *}}\end{array}$ & $\begin{array}{c}\odot .016 \\
{[\odot . \odot \odot 2]^{* * *}}\end{array}$ & $\begin{array}{c}0.011 \\
{[\odot .0 \odot 4]^{* * *}}\end{array}$ & $\begin{array}{c}0.081 \\
{[0.010]^{* * *}}\end{array}$ & $\begin{array}{c}0.057 \\
{[0.037]}\end{array}$ \\
\hline $70^{\text {th }}$ & $\begin{array}{c}0.047 \\
{[0.003]^{\star \star *}}\end{array}$ & $\begin{array}{c}\odot .032 \\
{[\odot . \odot \odot 3]^{\star * *}}\end{array}$ & $\begin{array}{c}0.028 \\
{[\odot .008]^{\star * *}}\end{array}$ & $\begin{array}{c}\odot .133 \\
{[\odot . \odot 20]^{* * *}}\end{array}$ & $\begin{array}{c}\odot .024 \\
{[\odot .075]}\end{array}$ \\
\hline $80^{\text {th }}$ & $\begin{array}{c}0.074 \\
{[\odot .005]^{* * *}}\end{array}$ & $\begin{array}{c}0.054 \\
{[\odot .0 \odot 5]^{* * *}}\end{array}$ & $\begin{array}{c}0.066 \\
{[\odot .010]^{* * *}}\end{array}$ & $\begin{array}{c}\odot .153 \\
{[\odot . \odot 27]^{* * *}}\end{array}$ & $\begin{array}{c}-0.2 \\
{[0.102]^{\star}}\end{array}$ \\
\hline $90^{\text {th }}$ & $\begin{array}{c}0.113 \\
{[0.008]^{* * *}}\end{array}$ & $\begin{array}{c}\odot .092 \\
{[\odot .0 \odot 8]^{* * *}}\end{array}$ & $\begin{array}{c}0.116 \\
{[0.020]^{* * *}}\end{array}$ & $\begin{array}{c}0.077 \\
{[0.064]}\end{array}$ & $\begin{array}{c}-0.29 \\
{[0.207]}\end{array}$ \\
\hline Controls & $\begin{array}{c}\text { Median Wage } \\
\text { Change } \\
1977 \text { dummy }\end{array}$ & $\begin{array}{c}(1)+ \\
\text { Current \& } \\
\text { Lagged } \\
\text { Regional } \\
\text { U/E Rates }\end{array}$ & \multicolumn{3}{|c|}{ (2) + Inflation \& Inflation*Turnover } \\
\hline
\end{tabular}

Notes:
a. Report Least Squares estimates, weighted by cell (occupation, region, year) size.
b. Uses nominal wage change percentiles for job stayers, re-weighted for changes in adjusted lagged wage, age, age ${ }^{2}$, sex, region (including London dummy), 2-digit industry, 2-digit occupation, and major union coverage.
c. Standard errors robust to non-independence within years.
d. $*$ significant at the $10 \%$ level; $* *$ significant at the $5 \%$ level; *** significant at the $1 \%$ level. 